\title{
Sills máficos da Suíte Intrusiva Huanchaca - SW do Cráton Amazônico: registro de magmatismo fissural relacionado à ruptura do Supercontinente Rodínia
}

\author{
Gabrielle Aparecida de Lima', Maria Zélia Aguiar de Sousa², Amarildo Salina Ruiz', \\ Manoel Souza D’Agrella Filho ${ }^{4}$ \& Paulo Vasconcelos ${ }^{5}$
}

\begin{abstract}
Resumo A Serra Ricardo Franco é constituída pelos estratos sub-horizontais do Grupo Aguapeí (Formações Fortuna, Vale da Promissão e Morro Cristalina, da base para o topo), pelos sills máficos da Suíte Intrusiva Huanchaca e pelos cherts e silexitos da Unidade Tramposo. Este trabalho objetiva apresentar os dados geológicos, petrográficos, geoquímicos e geocronológicos dos sills máficos pertencentes à Suíte Intrusiva Huanchaca, na porção norte da Serra Ricardo Franco, inseridos no Terreno Paraguá, SW do Cráton Amazônico, e discutir o provável significado tectônico deste evento ígneo. O mapeamento geológico permitiu a identificação de dois sills, alojados nos argilitos da Formação Vale da Promissão. Petrograficamente, as rochas dos sills são maciças, de granulação fina a média e cor cinza-esverdeado a preta. Apresentam texturas equi a inequigranulares e composição gabroica. Dados geoquímicos evidenciam natureza subalcalina do tipo toléitica para o magmatismo gerador destes sills em ambiente geotectônico correspondente à intraplaca continental e os valores do índice de magnésio (mg\#), variando entre 0,25 e 0,38, indicam magma basáltico evoluído. Os enxames de diques máficos das Suítes Intrusivas Huanchaca, Rancho de Prata e Rio Perdido, bem com os sills máficos Huanchaca e Salto do Céu, formaram-se entre 1040 a $850 \mathrm{Ma}$, e são constituídos por diabásios e gabros com afinidade toleítica. Este episódio magmático máfico constitui uma LIP (Large Igneous Province), gerada pela extensão crustal com vetor deslocamento NNW, que precedeu a dispersão do Supercontinente Rodínia.
\end{abstract}

Palavras-chave: Sills máficos, Cráton Amazônico, Suíte Intrusiva Huanchaca, Magmatismo Intracontinental.

\begin{abstract}
The mafic Sills of Huanchaca Intrusive Suite (SW of Amazonian Cráton) - are the record of a fissural magmatism related to the break-up of the Rodinia Supercontinent. The Ricardo Franco hill is comprised by sub-horizontal layers of the Aguapeí Group (Fortuna, Vale da Promissão and Morro Cristalina Formations, from bottom to top), mafic sills from the Huanchaca Intrusive Suite, and cherts and silexites of Tramposo Unit. This work presents geologic, petrographic, geochemical and geochronological (Ar-Ar) data of mafic sills belonging to the Huanchaca Intrusive Suite inserted in the Paraguá Terrane, SW of Amazonian Cráton, and discuss the possible tectonic significance of this igneous event. Two sills are identified intruding mudstones of the Vale da Promissão Formation. Petrographically, the mafic rocks are isotropic, fine to medium grained and greenish-gray to black color. They show equi to inequigranular textures and gabbroic composition. Geochemically the sills are subalkaline tholeiitic basalts and tectonically they are related to a continental intraplate environment. The magnesium index ( $\mathrm{mg} \#$ ) values vary between 0.25 and 0.38 , indicating evolved basaltic magmas. Data ${ }^{40} \mathrm{Ar}^{-39} \mathrm{Ar}$ isotopic ages indicate plateaus of $1040 \pm 40 \mathrm{Ma}$ for amphibole and $948 \pm 5 \mathrm{Ma}$ for plagioclase, the first (amphibole) is the best estimate of the age of injection of sills. The sills and mafic dykes Huanchaca, along with Rancho de Prata and Rio Perdido Intrusives Suites and sills (Salto do Céu Intrusive Suite) of the southwestern sector of the Amazonian Cráton, all described as diabases and gabbros of tholeiitic affinity, form a large igneous province (LIP), generated by crustal extension with a NNW displacement vector, preceding the dispersion of Rodinia Supercontinent.
\end{abstract}

Keywords: mafic sills, Amazonian Craton, Huanchaca Intrusive Suite, Intracontinental Magmatism.

1 - Programa de Pós-graduação em Geociências, Departamento de Recursos Minerais, Instituto de Ciências Exatas e da Terra, Universidade Federal de Mato Grosso, Cuiabá (MT), Brasil. Email: gabilimagel@gmail.com

2 - Departamento de Recursos Minerais, Instituto de Ciências Exatas e da Terra, Universidade Federal de Mato Grosso, Cuiabá (MT), Brasil. Email: prof.mzaguiar@gmail.com

3 - Departamento de Geologia Geral, Instituto de Ciências Exatas e da Terra, Universidade Federal de Mato Grosso, Cuiabá (MT), Brasil. Email: asruiz@gmail.com

4 - Departamento de Geofísica, Instituto de Astronomia, Geofísica e Ciências Atmosféricas, Universidade de São Paulo, São Paulo (SP), Brasil. Email: dagrella@iag.usp.br

5 - University of Queensland, Brisbane, Austrália. Email: paulo@earth.uq.edu.au 
INTRODUÇÃO Expressivo magmatismo básico localizado na porção Sul/Sudoeste do Cráton Amazônico, de idade toniana, tem sido descrito por vários autores (Litherland et al. 1986; Araújo et al. 1982; Sécolo et al. 2008; Lima 2008; Corrêa da Costa et al. 2008, 2009, D'Agrella Filho et al. 2010; Ruiz et al. 2005, 2009, 2010a). Segundo os últimos autores, este evento representa um LIP (Large Igneous Province).

O sudoeste do Cráton Amazônico em Mato Grosso, especificamente na região limítrofe Brasil-Bolívia, nas proximidades do município de Vila Bela da Santíssima Trindade, é caracterizado pela ocorrência de rochas pertencentes ao Terreno Paraguá, que se estende do oeste da Bolívia ao extremo ocidente do estado de Mato Grosso (Fig. 1), o qual foi aglutinado ao Cráton Amazônico ao final da Orogenia San Ignácio (1.4 a $1.28 \mathrm{Ga}$ ) e reativado parcialmente durante a Orogenia Sunsás $(1.1$ a $0.9 \mathrm{Ga})$. A área de estudo deste trabalho está localizada na porção leste deste terreno, ao longo da Serra Ricardo Franco ou Huanchaca, como é conhecida em território boliviano, a qual é constituída por sedimentos do Grupo Aguapeí (Formações Fortuna, Vale da Promissão e Morro Cristalina), intrusões (sills) máficas (Suíte Intrusiva Huanchaca) e sedimentos terciários (Unidade Tramposo) e quaternários. Do ponto de vista tectônico, esta área corresponde à parte do Terreno Paraguá não afetada pela orogenia Sunsás.

Os sills máficos da Suíte Intrusiva Huanchaca, alojados na Formação Vale da Promissão, foram escolhidos como objeto deste trabalho, que consta de mapeamento geológico sistemático na escala de 1:50.000, estudos petrográficos, geoquímicos e geocronológicos, bem como, reconhecimento dos litotipos que ocorrem em sua adjacência. Os resultados obtidos contribuem para o conhecimento da evolução geológica da porção sudoeste do estado de Mato Grosso, limite Brasil-Bolívia, particularmente sobre o magmatismo básico neoproterozoico relacionado ao estágio de ruptura do Supercontinente Rodínia.

CONTEXTO GEOLÓGICO REGIONAL O Cráton Amazônico, localizado na parte norte da América do Sul corresponde a uma das principais entidades geotectônicas pré-cambrianas do mundo. A concepção mais aceita para a evolução do cráton, proposta por Cordani et al. (1979), seguida e modificada por Tassinari (1981), Cordani \& Brito Neves (1982), Teixeira et al. (1989), Tassinari (1996), Tassinari \& Macambira (1999), Tassinari et al. (2000), Tassinari \& Macambira (2004), Santos et al. (2000, 2008), Ruiz (2005), dentre outros, fundamenta-se na Teoria da Tectônica Global ou de Placas, a qual defende a ocorrência, durante o Arqueano, Paleo e Mesoproterozoico, de uma sucessão de arcos magmáticos envolvendo a formação de material juvenil, além de processos subordinados de retrabalhamento crustal.

Ruiz (2005) apresenta a compartimentação tectônica-geocronológica do Cráton, considerando o Maciço/Bloco Rio Apa, que aflora no Brasil (Mato Grosso do Sul) e Paraguai entre os sedimentos da Bacia do Pantanal, como parte integrante (extremo sul) do Cráton Amazônico.

O sudoeste do Cráton Amazônico exposto em Mato Grosso guarda registros geológicos e tectônicos que se estendem do Paleo ao Neoproterozoico, culminando com a consolidação do Supercontinente Rodínia, apresentando uma evolução tectônica policíclica caracterizada pela superposição de episódios orogênicos. Há diversas propostas de compartimentação tectônica para esta porção do Cráton, dentre as quais se destacam: Monteiro et al. (1986); Saes \& Fragoso César (1996); Saes (1999); Geraldes et al. (2001), Matos et al. (2004), Ruiz $(2005,2009)$. Adota-se neste trabalho a sugerida por Ruiz (2009) que, com base na evolução geológica que antecede a Orogenia Sunsás (1.1 a $0.9 \mathrm{Ga})$, divide a região em cinco Terrenos, sendo eles: Paraguá, Rio Alegre, Jauru, Alto Guaporé e Nova Brasilândia.

Ruiz (2009) e Bettencourt et al. (2010) adotaram o termo Terreno Paraguá, para denotar um terreno composto por rochas do embasamento paleoproterozoico (Complexo Gnáissico Chiquitania, Grupo Xistos San Ignácio e Complexo Granulítico Lomas Manechis) e granitoides mesoproterozoicos (Complexo Granitoide Pensamiento), amalgamados ao proto-Cráton Amazônico durante a orogenia Rondoniano-San Ignácio. Esse embasamento paleo-mesoproterozoico encontra-se recoberto, por discordância erosiva, pelos sedimentos do Grupo Aguapeí, que retrata uma bacia intracontinental ou do tipo aulacogênica (Saes 1999, Teixeira et al. 2010).

Segundo Ruiz (2009), no Terreno Paraguá são reconhecidas duas orogêneses que precederam a Orogenia Sunsás: Orogenia Lomas Manechis (1.74 a 1.69 Ga) e Orogenia San Ignácio (1.4 a 1.28 Ga) (Boger et al. 2005, Ruiz 2005, Santos et al. 2008).

O magmatismo neoproterozoico, desenvolvido após a orogenia Sunsás, que ocorre no sul e sudoeste do Cráton Amazônico, é de natureza bimodal e está representado pelas Suítes Intrusivas Huanchaca, Salto do Céu, Rancho de Prata, Rio Perdido, Guapé, Sunsás e Granito Vila Bela (Tab. 1 e Fig. 1), sugerindo uma tentativa de ruptura continental.

GEOLOGIA E PETROGRAFIA A Serra Ricardo Franco/Huanchaca, corresponde a uma meseta alinhada, cujo eixo principal tem direção $\mathrm{N} 30^{\circ}-40^{\circ} \mathrm{W}$, sendo constituída pelos estratos sub-horizontais do Grupo Aguapeí, sills máficos da Suíte Intrusiva Huanchaca, 


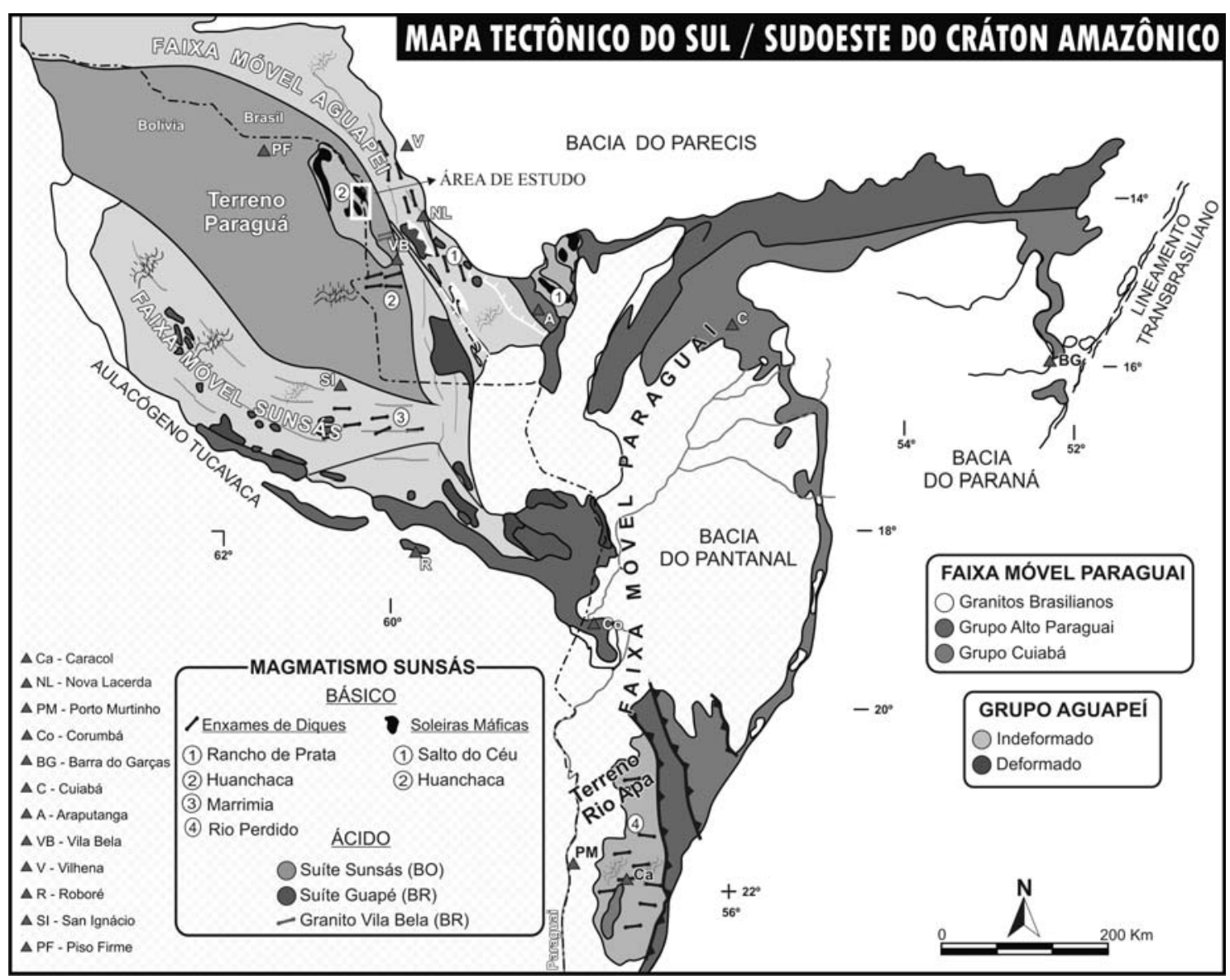

Figura 1 - Mapa tectônico do Sul/Sudoeste do Cráton Amazônico (extraído de Ruiz et al. 2010b).

Tabela 1 - Sumário das unidades litoestratigráficas da LIP com respectivas idades e localização no S-SW do Cráton Amazônico. BO - Bolívia, BR - Brasil. (a) Litherland et al. (1986), (b) Santos et al. (1979), (c) Barros et al. (1982) e Elming et al. (2009), (d) Araújo (2003), (e) Araújo et al. (1982), (f) Boger et al. (2005).

\begin{tabular}{cccc}
\hline \multicolumn{1}{c}{ Unidade } & Descrição & $\begin{array}{c}\text { Idade } \\
\text { (Ma) }\end{array}$ & Localização \\
\hline Suíte Intrusiva Huanchaca & diques e sills máficos & $\begin{array}{c}918 \pm 20(\mathrm{~K}-\mathrm{Ar}) \\
936 \pm 20(\mathrm{~K}-\mathrm{Ar})\end{array}$ & $\begin{array}{c}\text { (a) Terreno Paraguá - BO } \\
\text { (b) Terreno Paraguá - BR }\end{array}$ \\
\hline Suíte Intrusiva Salto do Céu & sills máficos & $\begin{array}{c}\text { (RT) } 875 \pm 21 \\
\text { (Pl) } 960 \pm 21\end{array}$ & (c) Terreno Jauru - BR \\
\hline Suíte Intrusiva Rancho de Prata & diques máficos & ----- & Terreno Jauru - BR \\
\hline Suíte Intrusiva Rio Perdido & diques máficos & $914 \pm 9(\mathrm{~K}-\mathrm{Ar})$ & (e) Terreno Rio Apa - BR \\
\hline Granito Vila Bela & diques graníticos & ----- & Terreno Paraguá - BR \\
\hline Suíte Intrusiva Guapé & corpos graníticos & $917 \pm 18(\mathrm{U}-\mathrm{Pb})$ & (d) Faixa Móvel Aguapeí - BR \\
\hline Suíte Intrusiva Sunsás & corpos graníticos & $1076 \pm 18(\mathrm{U}-\mathrm{Pb})$ & (f) Faixa Móvel Sunsás - BO \\
\hline
\end{tabular}

cherts e silexitos da Unidade Tramposo (Lima 2008) e coberturas aluvionares (Fig. 2). Estas unidades litoestratigráficas não apresentam registros de deformação penetrativa, bem como metamorfismo regional. Na borda NE da serra, no Brasil, falhas regionais, normais, bascularam as camadas do Grupo Aguapeí, deixando-as com mergulhos íngremes de cerca de $80-85^{\circ}$ para o quadrante NE.

A Suíte Intrusiva Huanchaca, na área em questão, está representada por dois sills que afloram sob a forma 


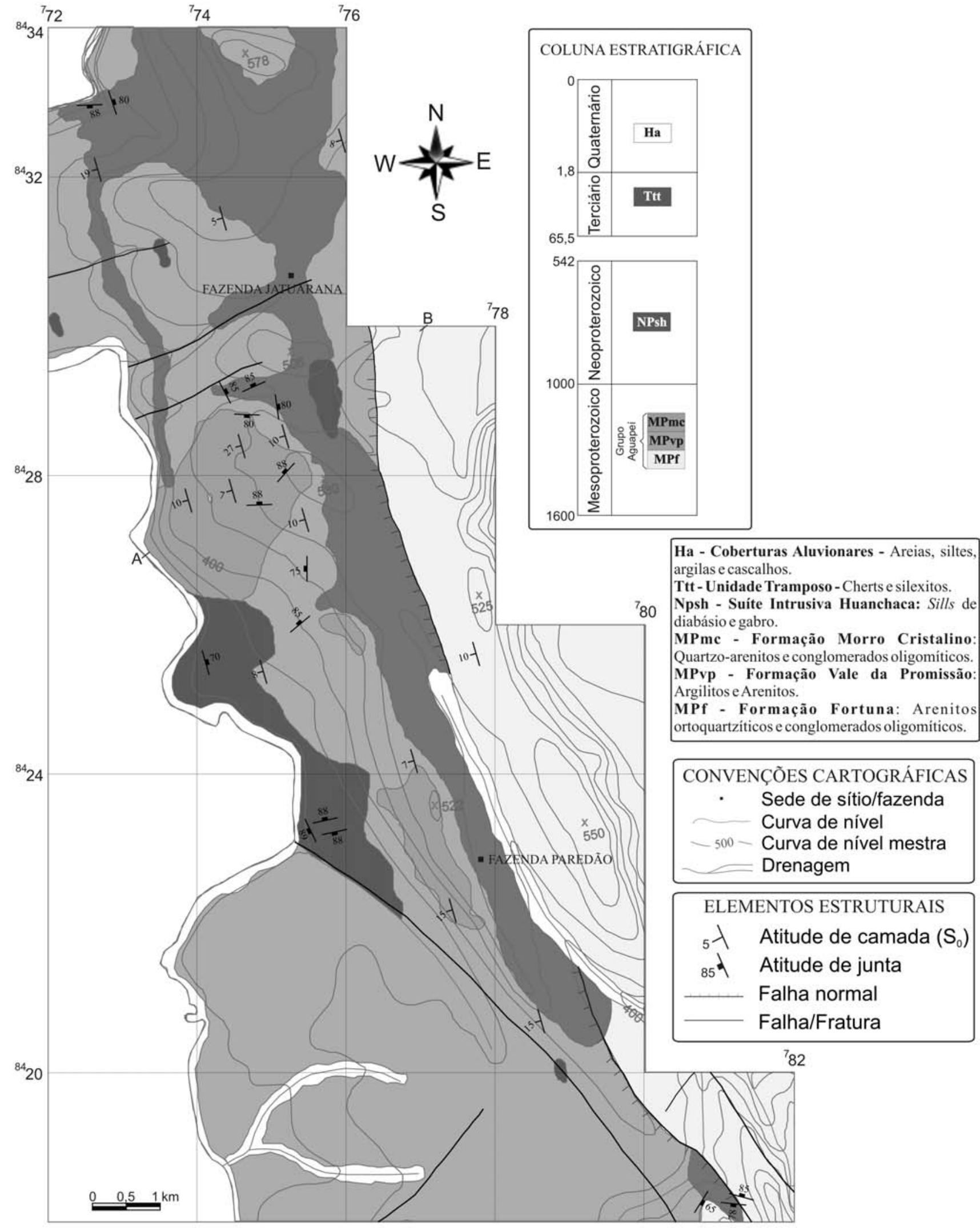

Figura 2 - Mapa Geológico da porção norte da Serra Ricardo Franco (extraído de Lima 2008). 
de matacões e lajedos (Figs. 3B e C), alojados nos pelitos e arenitos da Formação Vale da Promissão, Grupo Aguapeí, sendo o maior com cerca de $50 \mathrm{~m}$ de espessura que compreende o corpo de maior extensão (Fig. 2). O segundo localiza-se no extremo sul da área e de menor expressão (Fig. 2). Os contatos com as encaixantes (Fig. 3A) são sempre abruptos, paralelos ao acamadamento, não sendo reconhecidas feições de metamorfismo térmico.

Macroscopicamente, as rochas são maciças de granulação fina a média variando de melanocráticas a ultramáficas e cor cinza-esverdeado a preta (Fig. 3D). Apresentam texturas equi a inequigranulares e composição gabroica.

A partir do estudo detalhado de trinta lâminas delgadas, que consistiu de descrição de texturas, paragêneses primária e de alteração, bem como, definição das composições modais, foi possível a caracterização petrográfica das rochas pertencentes à Suíte Intrusiva Huanchaca, que ocorrem na região da $\mathrm{Fa}-$ zenda Paredão.
Os sills estudados são constituídos por rochas holocristalinas de textura subofítica (Fig. 4B) a ofítica (Fig. 4A) e, mais raramente, intergranular, fina a média, marcada pela trama de ripas de plagioclásio e cristais de piroxênio e, por vezes, anfibólio. Rochas cumuláticas, de ocorrência restrita, foram identificadas com paragênese e texturas semelhantes diferenciando-se pela presença de olivina e grande quantidade de máficos.

As rochas consistem, essencialmente, de plagioclásio, piroxênio, anfibólio, opacos, e em algumas delas, feldspato alcalino e quartzo com intercrescimento gráfico (Fig. 4G), tendo como minerais de alteração pós-magmática e acessórios: biotita, clorita, talco, titanita, apatita, argilo-minerais, epidoto/clinozoizita, sericita, calcita e serpentina. A olivina é encontrada em poucas amostras que correspondem a cumulatos perfazendo até $40 \%$ de seu volume modal.

Texturas localizadas, incomuns segundo MacKenzie et al. (1982), são reconhecidas nestas rochas, tais como intercrescimento radiado, constituído

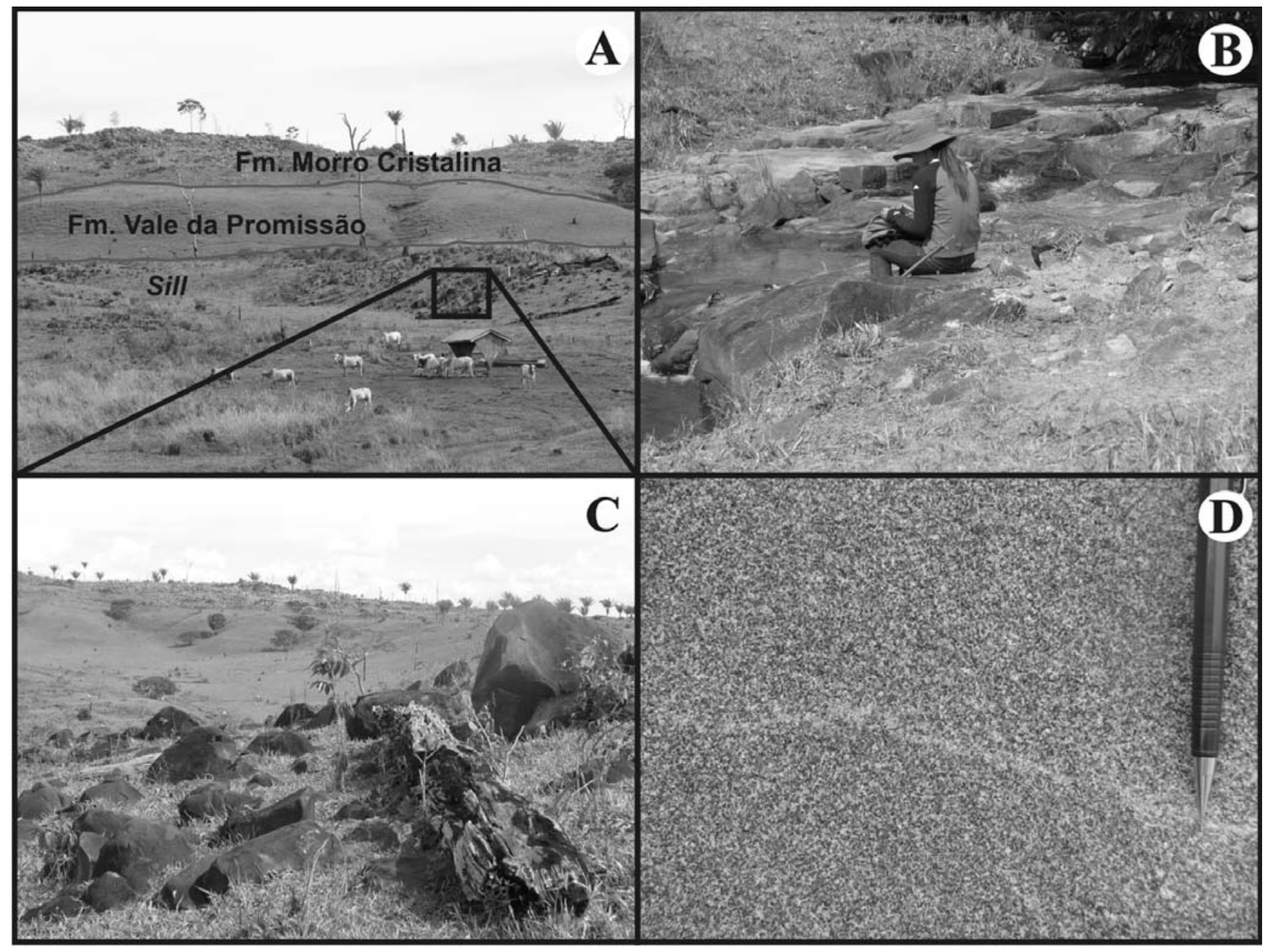

Figura 3 - A) Contato do sill com a Formação Vale da Promissão. Formas de afloramentos dos sills: B) lajedos e C) matacões. D) Aspecto macroscópico das rochas da Suíte Intrusiva Huanchaca ilustrando cor cinza-esverdeado. 


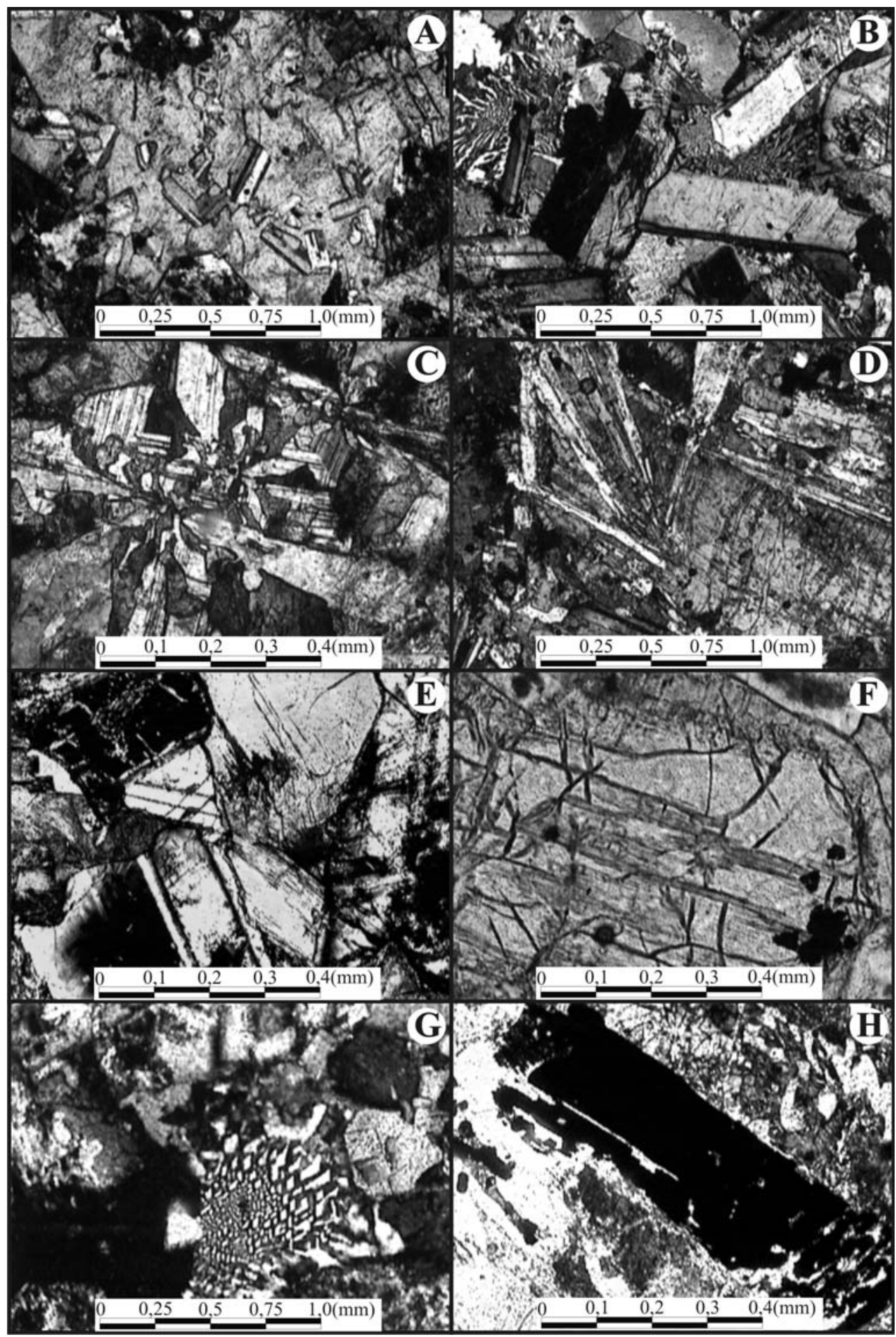

Figura 4 - Fotomicrografias ilustrando: A) textura ofítica formada por cristal de augita incluindo minúsculas ripas euédricas a subédricas de plagioclásio. B) textura subofítica formada por cristais tabulares de plagioclásio e prismáticos de piroxênio com geminação setorial, parcialmente uralitizados e intercrescimento gráfico. C) intercrescimento radiado, constituído por dois cristais de plagioclásio, perpendiculares entre si em um único cristal de piroxênio. D) leques formados por ripas divergentes de plagioclásio intercaladas por piroxênio. E) detalhe de cristais de plagioclásio com percolação de óxido de ferro e piroxênio parcialmente uralitizado. F) cristal de olivina com fraturamentos preenchidos por serpentina, seu principal produto de alteração e também com textura coronítica, formada por piroxênio. G) intercrescimento gráfico. $H$ ) desopatização, intercrescimento simplectítico, e textura gráfica na parte superior direita. Polarizadores cruzados em todas as imagens. 
por dois cristais de plagioclásio, perpendiculares entre si em um único cristal de piroxênio (Fig. 4C); bem como, leques formados por ripas divergentes de plagioclásio intercaladas por piroxênio (Fig. 4D).

O plagioclásio, identificado como andesina pelo método estatístico de Michel Levy (Kerr 1959), ocorre incluso nos cristais de piroxênio ou intersticial entre eles e apresenta hábito tabular ou em ripas menores, exibindo com frequência geminação polissintética do tipo albita ou periclina, por vezes combinadas, e subordinadamente, macla Carlsbad. Algumas amostras exibem evidências de processos de alteração, tais como, argilização, sericitização e, frequentemente, saussuritização com desenvolvimento de epidoto/clinozoizita, sericita e calcita, sem tipificar metamorfismo de baixo grau.

Os feldspatos alcalinos ocorrem em pequena percentagem e, quando observados, exibem sempre intercrescimento de quartzo que caracteriza textura gráfica, sugerindo contaminação crustal com assimilação de rochas encaixantes ricas em sílica, pertencentes ao Grupo Aguapeí.

Os piroxênios, reconhecidos como augita, pigeonita e hyperstênio, apresentam-se euédricos a subédricos com hábito prismático, ou anédricos com discreto pleocroísmo em tons rosa e às vezes, geminação setorial e/ou zonação. Ocorrem comumente uralitizados nos traços de clivagens e fraturas, exibindo textura coronítica frequente, com bordas de reação formadas principalmente por anfibólio, mas também por clorita, talco e serpentina. Esta paragênese de alteração pode substituí-los parcialmente (Fig. 4E) ou, algumas vezes pseudomorfizá-los, de maneira que a fase primária é encontrada apenas como minúsculos relictos.

Os anfibólios estão representados por hornblenda e actinolita, ambos como produtos de transformação da augita, formando textura coronítica. O primeiro é mais abundante e apresenta pleocroísmo verde-claro a marrom-claro ocorrendo em prismas subédricos e grãos anédricos; enquanto a actinolita exibe cor verde-claro e hábito principalmente fibroso. Alteram comumente para opacos, biotita, clorita e talco.

Os opacos ocorrem em quantidade expressiva, podendo representar produtos de alteração dos minerais máficos ou fases de cristalização primária, com forma cúbica, também em grãos anédricos disseminados por toda rocha ou com hábito dendrítico intercrescido com cristais de piroxênio e anfibólio caracterizando textura simplectítica (Fig. 4H); localmente, apresentam evidências de desopacitização com neoformação de biotita, clorita ou titanita. Esta última constitui coroa de reação de ilmenita ou pode representar fase primária acessória, ocorrendo em cristais romboédricos ou em grãos anédricos disseminados por toda a rocha. A apatita corresponde a uma fase primária acessória, ocorrendo em pequenos cristais aciculares inclusos principalmente no plagioclásio e piroxênio.

A olivina pode perfazer até $40 \%$ da rocha cumulática e sua composição mais magnesiana é estimada pelos seus produtos de alteração, tais como, serpentina e talco; bem como pelo seu caráter óptico positivo. Ocorre em grãos anédricos com bordas de reação para piroxênio, caracterizando textura coronítica (Figs. 4E e F), e com fraturamento típico, preenchido principalmente por serpentina de hábito fibroso. Por vezes, apresenta-se alterada, podendo estar totalmente pseudomorfisada ou ocorrer apenas como relictos.

GEOQUÍMICA DE ROCHA TOTAL Foram selecionadas dezessete amostras para análises geoquímicas, não contemplando as rochas cumuláticas, tidas como as mais representativas, considerando sua distribuição na área de estudo, bem como sua diversidade textural e mineralógica. As amostras foram britadas e pulverizadas no Laboratório de Preparação de Amostras do Departamento de Recursos Minerais da Universidade Federal de Mato Grosso. As análises químicas para determinação das concentrações de elementos maiores e menores por ICP-MS e elementos traço, incluindo terras raras, por ICP-ES, foram realizadas em dois laboratórios distintos (Acme Analytical Laboratories, Vancouver, Canadá, e Activation Labs. Ontário, Canadá - Tabs. 2 e 3, respectivamente). O tratamento dos dados geoquímicos obtidos foi feito utilizando o software Minpet for Windows (versão 2.0, Minpet Geological Software; Richard 1995).

Nos diagramas de Fenner, figuras 5 e 6, optou-se por utilizar o índice de diferenciação $\mathrm{mg \#}[\mathrm{mg} \#=$ $\left.\mathrm{Mg}^{+2} /\left(\mathrm{Mg}^{+2}+\mathrm{Fe}^{+2}\right)\right]$, em porcentagem de peso calculado, assumindo a razão $\mathrm{Fe}_{2} \mathrm{O}_{3} / \mathrm{FeO}$ igual a 0,15 , buscando obter melhores tendências das variações químicas. Os valores do índice de magnésio para as rochas estudadas apresentaram variações entre 0,25 e 0,38 sugerindo tratar-se de magmas basálticos evoluídos.

De modo geral, as rochas apresentam nítidas variações composicionais dos elementos maiores com a evolução magmática, mostrando que com o decréscimo de mg\# há diminuição do teor de $\mathrm{Al}_{2} \mathrm{O}_{3}$, enquanto que os teores de $\mathrm{Fe}_{2} \mathrm{O}_{3}, \mathrm{Na}_{2} \mathrm{O}, \mathrm{MnO}, \mathrm{K}_{2} \mathrm{O}, \mathrm{P}_{2} \mathrm{O}_{5}, \mathrm{TiO}_{2}$ aumentam (Fig. 5), O aumento dos valores de $\mathrm{TiO}_{2}$, com o decréscimo de mg\#, demonstra que o fracionamento de óxidos Fe-Ti não foi importante na evolução magmática. Há uma pequena dispersão dos valores de $\mathrm{CaO}$, provavelmente resultante do alto grau de saussuritização dos plagioclásios, ou decréscimo no teor de anortita das amostras (Fig. 5F). Já nos diagramas mg\# versus elementos traço, somente o teor de Ni diminui com o decréscimo de mg\#, diferindo dos elementos $\mathrm{Ba}, \mathrm{Y}, \mathrm{La}$, $\mathrm{Nd}, \mathrm{Zr}, \mathrm{Rb}$, e Ce que tem seus teores acrescidos. 
Sills máficos da Suíte Intrusiva Huanchaca - SW do Cráton Amazônico: registro de magmatismo fissural relacionado à ruptura do Supercontinente Rodínia

Tabela 2 - Composição química das amostras dos sills da Suíte Intrusiva Huanchaca (elementos maiores em \%, traços e terras raras em ppm) obtidas no Acme Analytical Laboratories.

\begin{tabular}{|c|c|c|c|c|c|c|c|}
\hline Amostras & LG9 & LG14D & LG36 & LG37C & LG117 & RV2B & LG111 \\
\hline Coordenadas & $\begin{array}{l}778202 / \\
8421522\end{array}$ & $\begin{array}{l}772168 / \\
8432846\end{array}$ & $\begin{array}{l}775655 / \\
8426206\end{array}$ & $\begin{array}{l}775454 / \\
8426004\end{array}$ & $\begin{array}{l}772879 / \\
8430532\end{array}$ & $\begin{array}{l}776516 / \\
8427670\end{array}$ & $\begin{array}{l}774776 / \\
8431292\end{array}$ \\
\hline $\mathrm{SiO}_{2}$ & 53,46 & 53,99 & 53,00 & 54,63 & 54,37 & 53,47 & 53,42 \\
\hline $\mathrm{Al}_{2} \mathrm{O}_{3}$ & 14,13 & 14,12 & 14,80 & 14,56 & 14,48 & 14,61 & 14,54 \\
\hline $\mathrm{Fe}_{2} \mathrm{O}_{3}(\mathrm{~T})$ & 11,32 & 11,17 & 10,81 & 9,83 & 9,76 & 10,44 & 10,39 \\
\hline $\mathrm{MnO}$ & 0,17 & 0,17 & 0,16 & 0,16 & 0,16 & 0,16 & 0,16 \\
\hline $\mathrm{MgO}$ & 5,48 & 5,19 & 6,46 & 6,26 & 6,74 & 5,99 & 6,09 \\
\hline $\mathrm{CaO}$ & 9,25 & 8,79 & 9,08 & 7,83 & 8,93 & 9,01 & 9,85 \\
\hline $\mathrm{Na}_{2} \mathrm{O}$ & 2,24 & 2,19 & 2,14 & 2,35 & 2,18 & 2,18 & 2,10 \\
\hline $\mathrm{K}_{2} \mathrm{O}$ & 1,28 & 1,48 & 1,20 & 1,77 & 1,27 & 1,33 & 1,22 \\
\hline $\mathrm{TiO}_{2}$ & 0,99 & 1,06 & 0,86 & 0,86 & 0,88 & 0,91 & 0,90 \\
\hline $\mathrm{P}_{2} \mathrm{O}_{5}$ & 0,12 & 0,11 & 0,11 & 0,10 & 0,09 & 0,11 & 0,11 \\
\hline LOI & 1,30 & 1,40 & 1,10 & 1,30 & 0,80 & 1,50 & 0,90 \\
\hline Total & 99,72 & 99,71 & 99,71 & 99,73 & 99,72 & 99,72 & 99,70 \\
\hline $\mathrm{Ba}$ & 391 & 489 & 361 & 360 & 353 & 361 & 369 \\
\hline $\mathrm{Sr}$ & 185,30 & 185,90 & 194,80 & 171,70 & 171,70 & 186,80 & 176,20 \\
\hline $\mathrm{Y}$ & 29,20 & 33,50 & 25,80 & 26,60 & 25,20 & 26,10 & 26,10 \\
\hline $\mathrm{Zr}$ & 121,90 & 136,50 & 111,60 & 125,00 & 114,40 & 122,90 & 117,30 \\
\hline $\mathrm{Rb}$ & 51,60 & 58,40 & 41,00 & 49,80 & 34,20 & 45,20 & 44,60 \\
\hline $\mathrm{Nb}$ & 5,80 & 6,30 & 5,20 & 8,00 & 6,20 & 5,00 & 5,80 \\
\hline $\mathrm{La}$ & 19,30 & 24,10 & 17,40 & 19,00 & 18,60 & 18,60 & 17,80 \\
\hline $\mathrm{Ce}$ & 41,80 & 51,10 & 39,30 & 42,80 & 40,10 & 41,50 & 39,90 \\
\hline $\operatorname{Pr}$ & 5,04 & 6,83 & 4,61 & 4,94 & 4,69 & 4,83 & 4,77 \\
\hline $\mathrm{Nd}$ & 19,80 & 24,70 & 17,90 & 20,60 & 19,90 & 19,20 & 18,10 \\
\hline $\mathrm{Sm}$ & 4,45 & 5,97 & 4,08 & 4,26 & 3,82 & 4,23 & 4,07 \\
\hline $\mathrm{Eu}$ & 1,19 & 2,11 & 1,09 & 1,05 & 1,03 & 1,08 & 1,11 \\
\hline Gd & 4,64 & 6,19 & 4,23 & 4,38 & 4,22 & 4,42 & 4,32 \\
\hline $\mathrm{Tb}$ & 0,81 & 1,89 & 0,74 & 0,78 & 0,73 & 0,76 & 0,75 \\
\hline Dy & 4,52 & 6,19 & 4,31 & 4,33 & 4,01 & 4,49 & 4,42 \\
\hline Ho & 0,99 & 2,02 & 0,89 & 0,91 & 0,89 & 0,96 & 0,92 \\
\hline $\mathrm{Er}$ & 2,92 & 4,16 & 2,73 & 2,67 & 2,71 & 2,74 & 2,89 \\
\hline $\mathrm{Tm}$ & 0,45 & 1,37 & 0,40 & 0,41 & 0,39 & 0,40 & 0,43 \\
\hline $\mathrm{Yb}$ & 2,94 & 4,04 & 2,57 & 2,55 & 2,66 & 2,67 & 2,63 \\
\hline $\mathrm{Lu}$ & 0,41 & 1,35 & 0,40 & 0,40 & 0,36 & 0,40 & 0,40 \\
\hline $\mathrm{K}$ & 10626 & 12286 & 9961 & 14693 & 10543 & 11041 & 10128 \\
\hline $\mathrm{Ti}$ & 5935 & 6354 & 5155 & 5155 & 5275 & 5455 & 5395 \\
\hline $\mathrm{Ni}$ & 51 & 53 & 72 & 53 & 59 & 70 & 64 \\
\hline $\mathrm{mg} \#$ & 0,30 & 0,29 & 0,34 & 0,36 & 0,38 & 0,34 & 0,34 \\
\hline
\end{tabular}

Quando plotadas no diagrama baseado no conteúdo de sílica total versus álcalis, proposto por Le Bas et al. (1986; Fig. 7C) as rochas classificam-se como basaltos andesíticos, de natureza subalcalina evidenciada pelo diagrama de Irvine \& Baragar
(1971; Fig. 7A). No diagrama AFM (Irvine \& Baragar 1971; Fig. 7B) observa-se que todas as amostras seguem um trend toleítico, com destacado enriquecimento em $\mathrm{FeO}_{t}$ em relação aos álcalis. Quanto à ambiência tectônica, o gráfico $\mathrm{Zr}$ versus $\mathrm{Zr} / \mathrm{Y}$ de Pearce \& 
Tabela 3 - Composição química das amostras dos sills da Suíte Intrusiva Huanchaca (elementos maiores em \%, traços e terras raras em ppm) obtidas no Activation Labs.

\begin{tabular}{|c|c|c|c|c|c|c|c|c|c|c|}
\hline Amostras & RV01A & RV02C & RV2D & RV03A & RV04A & RV4B & RV05B & S2 & S3 & $\mathrm{S} 4$ \\
\hline Coordenadas & $\begin{array}{l}775851 / \\
8427681\end{array}$ & $\begin{array}{l}776516 / \\
8427670\end{array}$ & $\begin{array}{c}776516 / \\
8427670\end{array}$ & $\begin{array}{l}777203 / \\
8427665\end{array}$ & $\begin{array}{l}777351 / \\
8428051\end{array}$ & $\begin{array}{l}777351 / \\
8428051\end{array}$ & $\begin{array}{l}776948 / \\
8427874\end{array}$ & $\begin{array}{l}774997 / \\
8427687\end{array}$ & $\begin{array}{l}774413 / \\
8427703\end{array}$ & $\begin{array}{l}774172 / \\
8427691\end{array}$ \\
\hline $\mathrm{SiO}_{2}$ & 54,95 & 52,91 & 53,31 & 53,83 & 54,49 & 54,63 & 54,98 & 54,71 & 52,21 & 54,65 \\
\hline $\mathrm{Al}_{2} \mathrm{O}_{3}$ & 13,77 & 13,96 & 14,06 & 14,65 & 14,57 & 14,45 & 14,54 & 14,07 & 14,37 & 14,54 \\
\hline $\mathrm{Fe}_{2} \mathrm{O}_{3}(\mathrm{~T})$ & 11,53 & 11,65 & 11,92 & 10,36 & 10,49 & 10,89 & 10,28 & 10,82 & 10,06 & 10,46 \\
\hline $\mathrm{MnO}$ & 0,17 & 0,17 & 0,17 & 0,16 & 0,16 & 0,16 & 0,16 & 0,16 & 0,15 & 0,16 \\
\hline $\mathrm{MgO}$ & 4,83 & 5,17 & 4,62 & 6,56 & 6,01 & 5,92 & 5,98 & 5,63 & 6,14 & 6,04 \\
\hline $\mathrm{CaO}$ & 8,73 & 8,92 & 8,62 & 9,05 & 9,14 & 9,23 & 9,23 & 9,3 & 8,99 & 9,33 \\
\hline $\mathrm{Na}_{2} \mathrm{O}$ & 2,27 & 2,2 & 2,24 & 2,06 & 2,18 & 2,24 & 2,12 & 2,24 & 1,97 & 2,11 \\
\hline $\mathrm{K}_{2} \mathrm{O}$ & 1,77 & 1,4 & 1,38 & 1,06 & 1,35 & 1,31 & 1,26 & 1,43 & 1,19 & 1,22 \\
\hline $\mathrm{TiO}_{2}$ & 1,09 & 1,02 & 1,09 & 0,92 & 0,94 & 0,96 & 0,93 & 1,01 & 0,91 & 0,96 \\
\hline $\mathrm{P}_{2} \mathrm{O}_{5}$ & 0,17 & 0,14 & 0,15 & 0,12 & 0,13 & 0,13 & 0,13 & 0,13 & 0,13 & 0,13 \\
\hline LOI & 1,21 & 0,97 & 0,86 & 0,78 & 1,11 & 0,93 & 1,1 & 1,12 & 3,58 & 1,08 \\
\hline Total & 100,5 & 98,51 & 98,42 & 99,55 & 100,6 & 100,8 & 100,7 & 100,6 & 99,69 & 100,7 \\
\hline $\mathrm{Ba}$ & 493 & 414 & 439 & 250 & 384 & 384 & 392 & 408 & 256 & 380 \\
\hline $\mathrm{Sr}$ & 171 & 179 & 177 & 176 & 184 & 171 & 172 & 169 & 175 & 173 \\
\hline $\mathrm{Y}$ & 31 & 28 & 30 & 22 & 25 & 26 & 25 & 26 & 23 & 25 \\
\hline $\mathrm{Zr}$ & 153 & 133 & 146 & 116 & 124 & 130 & 121 & 136 & 120 & 129 \\
\hline $\mathrm{Rb}$ & 71 & 57 & 50 & 34 & 46 & 44 & 41 & 53 & 40 & 43 \\
\hline $\mathrm{Nb}$ & 6,0 & 5,0 & 6,0 & 5,0 & 5,0 & 5,0 & 5,0 & 5,0 & 5,0 & 5,0 \\
\hline $\mathrm{La}$ & 23,3 & 21,4 & 22,0 & 18,6 & 18,4 & 19,1 & 18,7 & 19,6 & 19,1 & 18,9 \\
\hline $\mathrm{Ce}$ & 49,1 & 44,8 & 46,1 & 39,2 & 39,0 & 40,3 & 39,4 & 41,7 & 40,3 & 40,2 \\
\hline $\operatorname{Pr}$ & 5,90 & 5,40 & 5,45 & 4,59 & 4,67 & 4,81 & 4,74 & 4,98 & 4,75 & 4,81 \\
\hline $\mathrm{Nd}$ & 23,5 & 21,3 & 21,5 & 18,2 & 18,7 & 19,1 & 18,9 & 20,0 & 18,7 & 18,8 \\
\hline $\mathrm{Sm}$ & 5,1 & 4,6 & 4,7 & 4,0 & 4,1 & 4,2 & 4,1 & 4,4 & 4,1 & 4,2 \\
\hline $\mathrm{Eu}$ & 1,40 & 1,33 & 1,31 & 1,15 & 1,19 & 1,20 & 1,17 & 1,22 & 1,15 & 1,18 \\
\hline $\mathrm{Gd}$ & 5,5 & 5,0 & 5,1 & 4,4 & 4,4 & 4,5 & 4,3 & 4,7 & 4,3 & 4,5 \\
\hline $\mathrm{Tb}$ & 1,0 & 0,9 & 0,9 & 0,8 & 0,8 & 0,8 & 0,8 & 0,9 & 0,8 & 0,8 \\
\hline Dy & 5,9 & 5,4 & 5,4 & 4,7 & 4,7 & 4,9 & 4,8 & 5,1 & 4,8 & 4,9 \\
\hline Ho & 1,2 & 1,1 & 1,1 & 0,9 & 1,0 & 1,0 & 1,0 & 1,1 & 0,9 & 1,0 \\
\hline $\mathrm{Er}$ & 3,5 & 3,2 & 3,3 & 2,8 & 2,9 & 3,0 & 2,9 & 3,1 & 2,8 & 2,9 \\
\hline $\mathrm{Tm}$ & 0,51 & 0,49 & 0,50 & 0,43 & 0,43 & 0,45 & 0,43 & 0,47 & 0,42 & 0,43 \\
\hline $\mathrm{Yb}$ & 3,3 & 3,2 & 3,2 & 2,7 & 2,7 & 2,8 & 2,7 & 3,0 & 2,7 & 2,8 \\
\hline $\mathrm{Lu}$ & 0,50 & 0,48 & 0,47 & 0,41 & 0,42 & 0,43 & 0,41 & 0,45 & 0,41 & 0,42 \\
\hline $\mathrm{K}$ & 14693 & 11622 & 11456 & 8799 & 11207 & 10875 & 10460 & 11871 & 9878 & 10128 \\
\hline $\mathrm{Ti}$ & 6564 & 6102 & 6576 & 5497 & 5653 & 5605 & 5563 & 6049 & 5431 & 5731 \\
\hline $\mathrm{Ni}$ & 40 & 50 & 40 & 60 & 60 & 60 & 40 & 50 & 60 & 50 \\
\hline $\mathrm{mg \#}$ & 0,27 & 0,28 & 0,25 & 0,36 & 0,34 & 0,32 & 0,34 & 0,31 & 0,35 & 0,34 \\
\hline
\end{tabular}

Norry (1979; Fig. 7D) discrimina essas rochas como basaltos intraplaca.

No diagrama multielementar (Fig. 8A), normalizado pelo manto primitivo (McDonough \& Sun 1995), observa-se anomalias negativas de $\mathrm{K}, \mathrm{Nb}, \mathrm{Sr}$ e
Ti e positivas de Ba e La. Para comparação são mostrados os padrões médios para Basaltos de Ilha Oceânica (OIB), Basaltos de Cordilheira Meso-oceânica Normal (N-MORB) e Enriquecido (E-MORB) (McDonough \& Sun 1995). Nota-se que o padrão das amostras dos sills 

ruptura do Supercontinente Rodínia
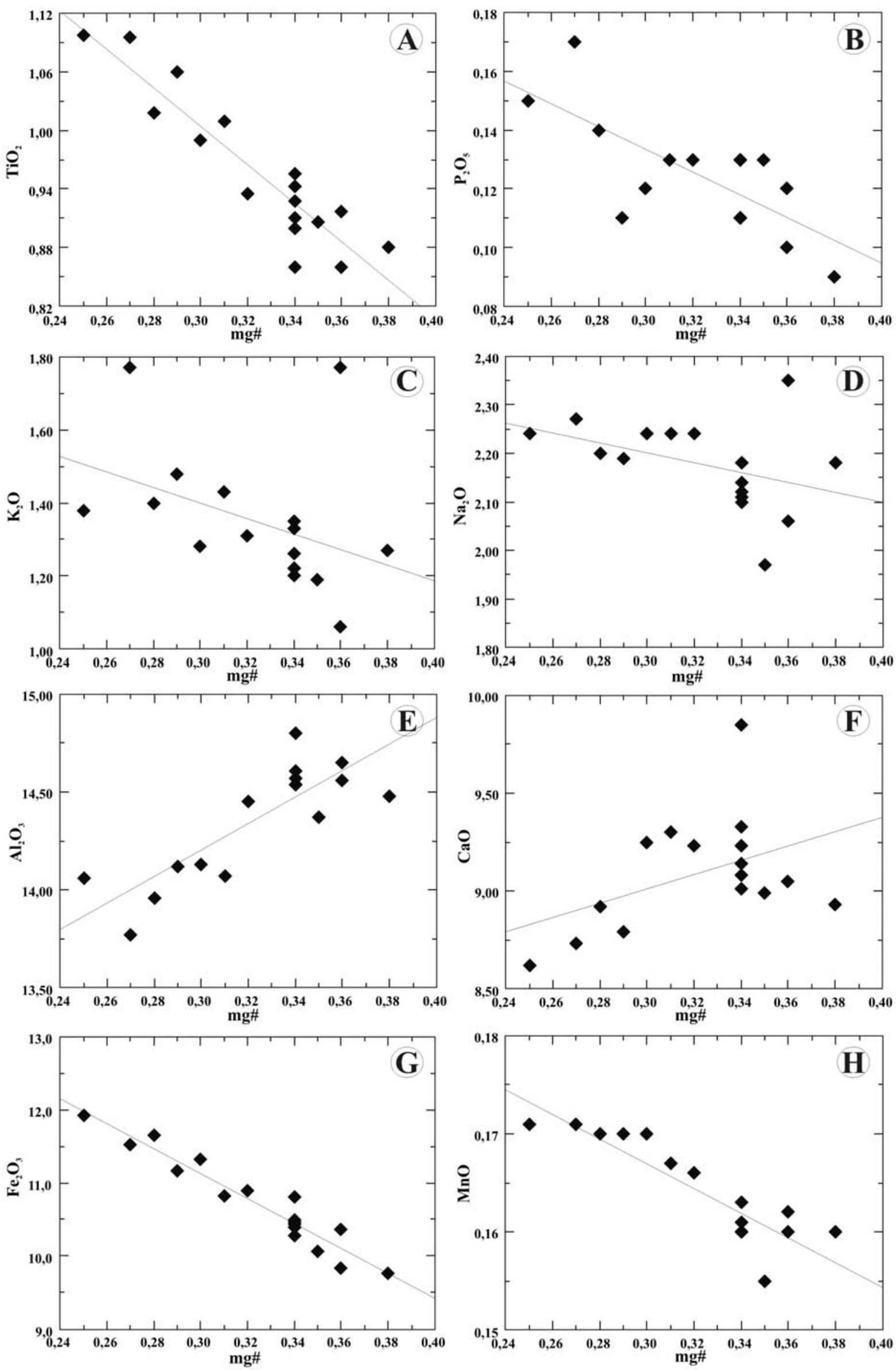

Figura 5 - Diagramas de variação mg\# versus óxidos de elementos maiores (\% em peso) das rochas da Suíte Intrusiva Huanchaca. 
Gabrielle Aparecida de Lima et al.
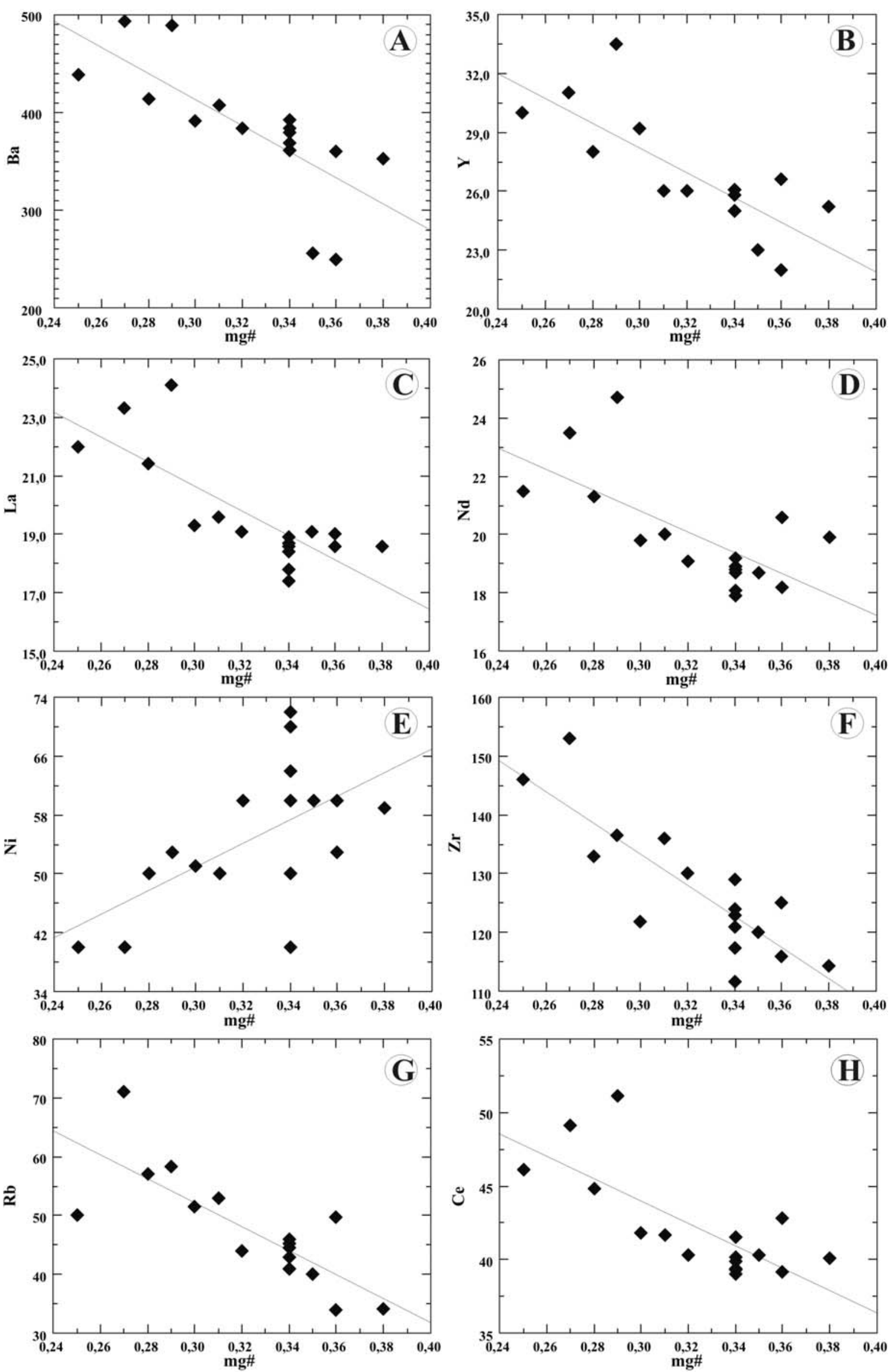

Figura 6 - Diagramas de variação mg\# versus elementos traço (ppm) das rochas da Suíte Intrusiva Huanchaca. 

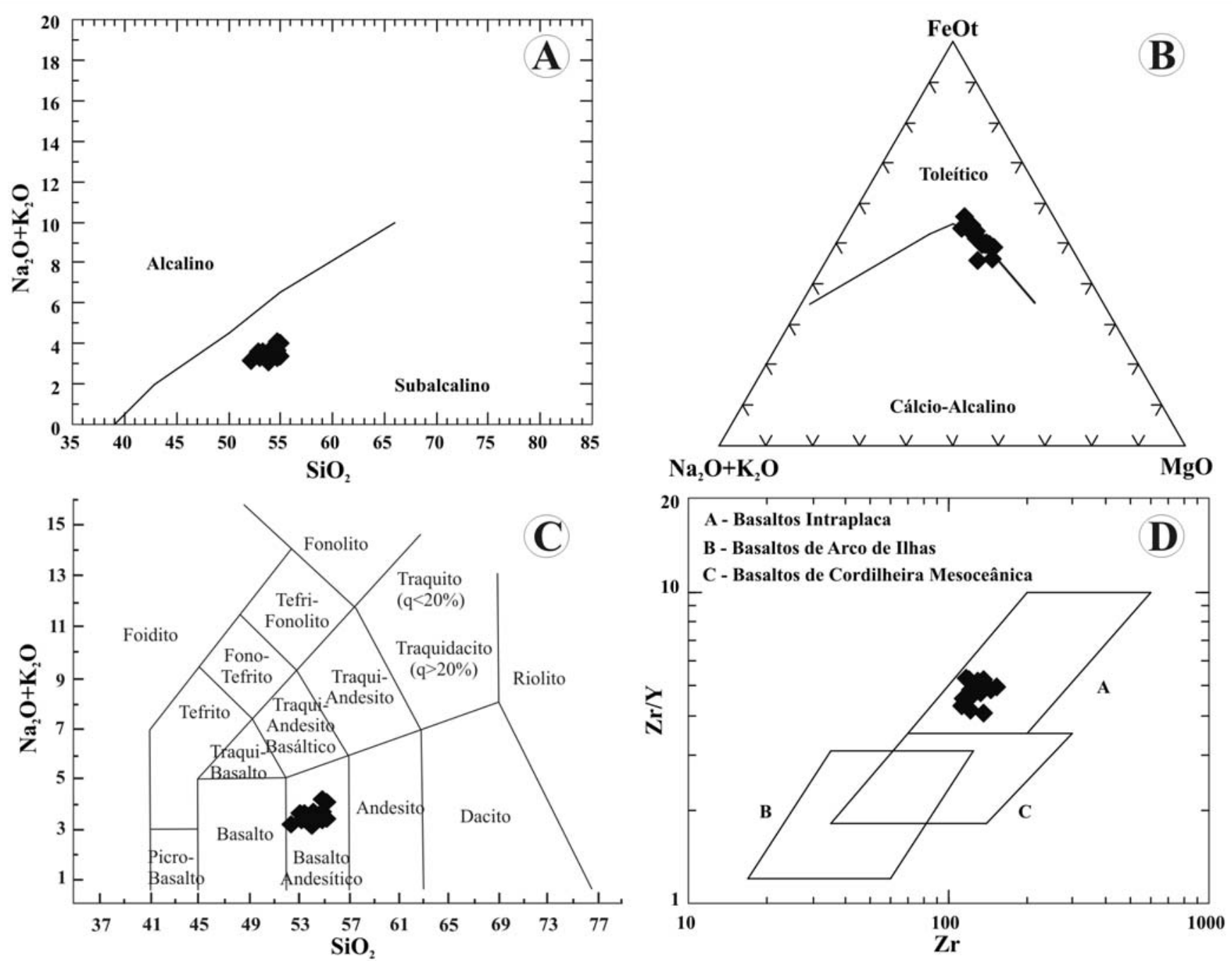

Figura 7 - Diagramas classificatórios dos sills da Suíte Huanchaca: (A) $\mathrm{Na}_{2} \mathrm{O}+\mathrm{K}_{2} \mathrm{O}$ versus $\mathrm{SiO}_{2}$ e (B) AFM de Irvine \& Baragar (1971), C) TAS de Le Bas et al. (1986), D) Zr vs Zr/Y de Pearce \& Norry (1979).

assemelha-se ao dos OIB, diferenciando-se apenas por apresentar anomalia negativa de $\mathrm{Nb}$, característica de ambiente continental.

Os padrões de distribuição dos elementos terras raras (ETR), normalizados para os valores do condrito segundo Boynton (1984; Fig. 8B), apresentam-se fortemente fracionados e enriquecidos em ETR leves em relação aos ETR pesados e uma discreta anomalia de $\mathrm{Eu}$. O padrão observado é mais comparável com o apresentado pelos OIB, sendo os sills Huanchaca um pouco menos enriquecidos nos ETR leves e empobrecidos nos ETR pesados em relação ao mesmo, isto é, apresenta razões $\mathrm{La} / \mathrm{Yb}$ mais baixas.

As razões $\mathrm{Zr}$ versus elementos incompatíveis têm mostrado ser uma boa ferramenta para o estudo das propriedades e dos processos de gênese das rochas e da investigação de heterogeneidade do manto, em consequência do pouco fracionamento desses elementos durante os processos de cristalização fracionada ou fusão parcial. Para as rochas estudadas (Fig. 9), exceto $\mathrm{Sr}$, observam-se correlações positivas entre $\mathrm{Zr}$ e $\mathrm{La}, \mathrm{Ce}$, Ti, Nd e Y com pequenas variações em suas razões $(\mathrm{Zr} /$ La 5,664 - 6,939; Zr/Ce 2,671 - 3,261; Zr/Ti 0,021 0,$022 ; \mathrm{Zr} / \mathrm{Nd} 5,526$ - 6,862; Zr/Y 4,075 - 5,273; Zr/Sr $0,573-0,895)$ sugerindo que os sills da Suíte Intrusiva Huanchaca resultam de fonte mantélica homogênea enriquecida em LILE e empobrecida em $\mathrm{Nb}$ e Ti.

\section{DADOS GEOCRONOLÓGICOS}

Análises ${ }^{40} \mathrm{Ar} /{ }^{39} \mathrm{Ar} \quad$ A amostra selecionada (LG-70; 775907,8427076 ) para análise isotópica ${ }^{40} \mathrm{Ar} /{ }^{39} \mathrm{Ar}$ foi triturada até alcançar granulação inferior a $2 \mathrm{~mm}$, sendo em seguida lavada em banho ultrassônico até sua limpeza completa. Logo depois, foi lavada por um período mínimo de 15 min, sequencialmente, em água destilada e em etanol absoluto e, posteriormente, seca ao ar. Os 

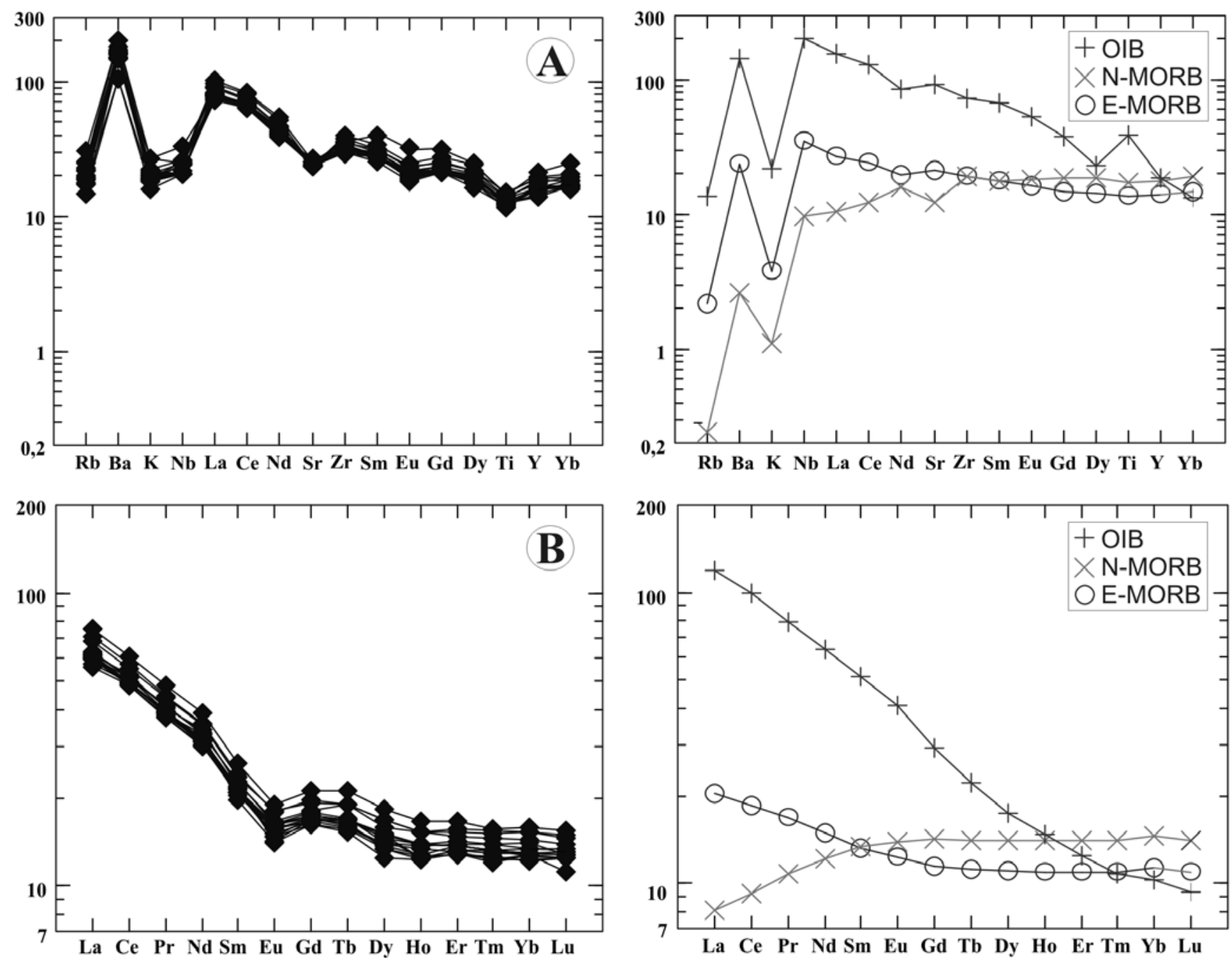

Figura 8 - A) Diagrama multielementar das rochas da Suíte Intrusiva Huanchaca normalizado pelo manto primitivo (McDonough \& Sun 1995). B) Diagrama de distribuição dos elementos terras raras (ETR) para as rochas da Suíte Intrusiva Huanchaca normalizados pelo condrito segundo Boynton (1984). Para efeito de comparação foram utilizados os padrões OIB, N-MORB e E-MORB de McDonough \& Sun (1995) e Boynton (1984), respectivamente.

grãos minerais (plagioclásio e anfibólio), com granulação entre 0,5 e $2 \mathrm{~mm}$, foram selecionados com auxílio de um microscópio binocular a partir do material limpo. Os minerais foram acondicionados em discos de alumínio junto com um padrão internacional (Fish Canyon Sanidine - idade 28,201 \pm 0,046 Ma; Kuiper et al. 2008), para monitoramento do fluxo de nêutrons, seguindo a geometria ilustrada em Vasconcelos et al. (2002). Os discos de irradiação foram fechados com tampas de alumínio, envolvidos em papel alumínio, selados em tubos de quartzo, dispostos num recipiente colunar de cádmio e posteriormente irradiado, em um reator tipo TRIGA na Universidade do Estado de Oregon-EUA, por 42 h, no período de 03 a 15 de dezembro de 2009.

Cada amostra foi aquecida gradualmente com um feixe de laser contínuo com tamanho de $2 \mathrm{~mm}$, para extração do Ar por fusão por etapas (step-heating) das amostras irradiadas. Este procedimento resulta em extrações de várias frações de gás a temperaturas crescentes analisadas individualmente no espectrômetro de massa MAP-215-50, utilizando o software "MassSpec Versão 7.527", desenvolvido pelo Centro de Geocronologia de Berkeley-EUA, os procedimentos analíticos estão descritos em Deino \& Potts (1990) e Vasconcelos et al. (2002). Os dados analíticos da tabela 4 foram obtidos no Laboratório da Universidade de Queensland-Austrália.

As duas idades plateaus obtidas, tanto para o plagioclásio (948 \pm 5 Ma; Fig. 10A) como para o anfibólio $(1040 \pm 40 \mathrm{Ma}$; Fig. 10B) indicam que o sistema $\mathrm{Ar} /$ Ar dos minerais datados permaneceu fechado, e todas as idades alcançadas nas diferentes temperaturas foram as mesmas, gerando um espectro de idades contínuo e 
Sills máficos da Suíte Intrusiva Huanchaca - SW do Cráton Amazônico: registro de magmatismo fissural relacionado à ruptura do Supercontinente Rodínia
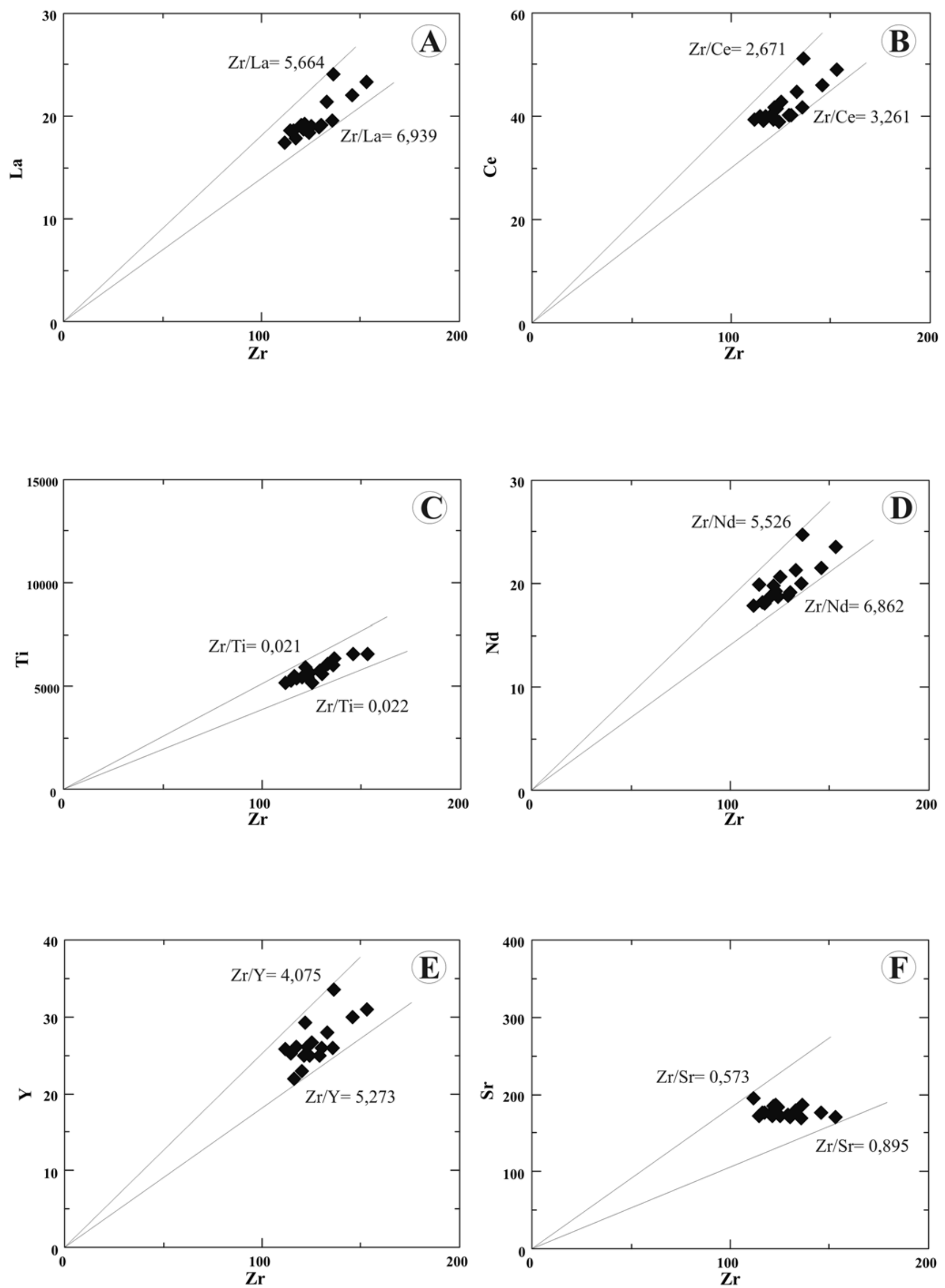

Figura 9 - Diagramas de correlação entre Zr versus elementos traço (incompatíveis) para as rochas da Suíte Intrusiva Huanchaca. 
Tabela 4 - Dados analíticos obtidos para plagioclásio e anfibólio da Suíte Intrusiva Huanchaca.

\begin{tabular}{|c|c|c|c|c|c|c|c|c|c|c|}
\hline $\begin{array}{l}\text { Amostra/ } \\
\text { Material }\end{array}$ & $\mathbf{N}^{0}$ LAB & ${ }^{40} \mathrm{Ar} /{ }^{39} \mathrm{Ar}$ & ${ }^{38} \mathrm{Ar} /{ }^{39} \mathrm{Ar}$ & ${ }^{37} \mathrm{Ar} /{ }^{39} \mathrm{Ar}$ & ${ }^{36} \mathrm{Ar} /{ }^{39} \mathrm{Ar}$ & ${ }^{40 *} \mathrm{Ar} /{ }^{39} \mathrm{Ar}$ & $\%^{40 * A r}$ & $\begin{array}{l}{ }^{40} \mathrm{Ar} \\
\text { (Mols) }\end{array}$ & $\begin{array}{l}\text { Idade } \\
\text { (Ma) }\end{array}$ & \pm (Ma) \\
\hline \multirow{20}{*}{ 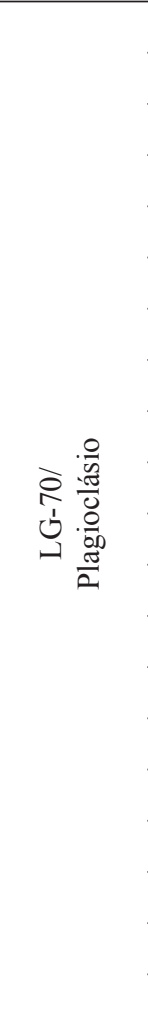 } & $6554-01 \mathrm{~A}$ & 103 & 0,072 & 38 & 0,058 & 91 & 86,1 & $3,32 \mathrm{E}-15$ & 1250 & 200 \\
\hline & 6554-01B & 59,64 & 0,0149 & 6,9 & 0,0108 & 57,21 & 95,48 & $6,98 \mathrm{E}-14$ & 877,9 & 6,9 \\
\hline & $6554-01 \mathrm{C}$ & 71,7 & 0,01201 & 3,44 & 0,0024 & 71,41 & 99,37 & $1,90 \mathrm{E}-13$ & 1042,6 & 5,3 \\
\hline & 6554-01D & 73,9 & 0,01331 & 0,8 & 0,0014 & 73,58 & 99,52 & $3,20 \mathrm{E}-13$ & 1066,5 & 5,1 \\
\hline & $6554-01 \mathrm{E}$ & 73,62 & 0,01374 & 1,05 & 0,00143 & 73,32 & 99,53 & $2,86 \mathrm{E}-13$ & 1063,7 & 4,3 \\
\hline & $6554-01 \mathrm{~F}$ & 70,59 & 0,01375 & 2,45 & 0,00271 & 70,09 & 99,12 & $1,57 \mathrm{E}-13$ & 1027,9 & 5,9 \\
\hline & $6554-01 \mathrm{G}$ & 69,81 & 0,016 & 3 & 0,00432 & 68,89 & 98,48 & $5,50 \mathrm{E}-14$ & 1014 & 10 \\
\hline & $6554-01 \mathrm{H}$ & 71,55 & 0,01336 & 2,64 & 0,00158 & 71,41 & 99,63 & $2,29 \mathrm{E}-13$ & 1042,6 & 5,4 \\
\hline & 6554-01I & 70,6 & 0,012 & 6,5 & 0,00328 & 70,4 & 99,32 & $5,00 \mathrm{E}-14$ & 1032 & 12 \\
\hline & $6554-01 \mathrm{~J}$ & 73,4 & 0,0172 & 5 & 0,0015 & 73,5 & 99,9 & 2,56E-14 & 1066 & 21 \\
\hline & $6554-02 \mathrm{~A}$ & 90,4 & 0,0496 & 21 & 0,1014 & 62,6 & 68,3 & $1,15 \mathrm{E}-14$ & 942 & 45 \\
\hline & 6554-02B & 58,66 & 0,02112 & 3,81 & 0,02182 & 52,57 & 89,4 & $1,30 \mathrm{E}-13$ & 820,6 & 5,6 \\
\hline & $6554-02 \mathrm{C}$ & 65,31 & 0,01155 & 0,82 & 0,00246 & 64,67 & 98,97 & $3,50 \mathrm{E}-13$ & 966,2 & 3,7 \\
\hline & 6554-02D & 64,69 & 0,01217 & 0,86 & 0,001611 & 64,31 & 99,36 & $1,04 \mathrm{E}-12$ & 962,1 & 3,1 \\
\hline & $6554-02 \mathrm{E}$ & 63,47 & 0,01189 & 0,374 & 0,000817 & 63,27 & 99,66 & $1,69 \mathrm{E}-12$ & 950 & 2,8 \\
\hline & $6554-02 F$ & 63,78 & 0,01513 & 2,22 & 0,00638 & 62,14 & 97,28 & $2,06 \mathrm{E}-13$ & 936,7 & 5,6 \\
\hline & $6554-02 \mathrm{G}$ & 64,02 & 0,01422 & 1,19 & 0,00507 & 62,65 & 97,78 & $1,50 \mathrm{E}-13$ & 942,7 & 4,9 \\
\hline & $6554-02 \mathrm{H}$ & 64,35 & 0,01359 & 2,62 & 0,004 & 63,47 & 98,46 & $4,28 \mathrm{E}-13$ & 952,3 & 3,5 \\
\hline & 6554-02I & 64,88 & 0,01299 & 5,1 & 0,00893 & 62,82 & 96,49 & $6,80 \mathrm{E}-14$ & 944,7 & 8,9 \\
\hline & 6554-02J & 64,6 & 0,0148 & 2,7 & 0,0092 & 62,2 & 96,1 & $2,71 \mathrm{E}-14$ & 937 & 20 \\
\hline \multirow{20}{*}{ 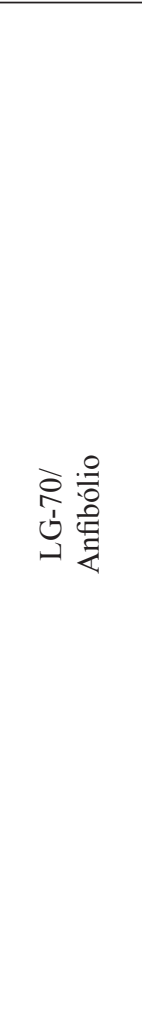 } & $6556-01 \mathrm{~A}$ & 240 & 0,141 & 184 & 0,59 & 90 & 32,7 & $6,88 \mathrm{E}-15$ & 1240 & 280 \\
\hline & 6556-01B & 299 & 0,155 & 4 & 0,702 & 89,9 & 30 & $4,03 \mathrm{E}-14$ & 1237 & 63 \\
\hline & $6556-01 \mathrm{C}$ & 159,6 & 0,0706 & 49 & 0,223 & 100,2 & 60,7 & $1,94 \mathrm{E}-14$ & 1337 & 67 \\
\hline & 6556-01D & 84,3 & 0,0391 & 18,1 & 0,0149 & 82,3 & 96,39 & $4,04 \mathrm{E}-14$ & 1160 & 18 \\
\hline & $6556-01 \mathrm{E}$ & 78,9 & 0,0407 & 6,3 & 0,00488 & 78,27 & 98,77 & 8,29E-14 & 1117,1 & 9,8 \\
\hline & $6556-01 \mathrm{~F}$ & 78,53 & 0,0383 & 2,4 & 0,00594 & 77,07 & 97,98 & 7,95E-14 & 1104,3 & 8,8 \\
\hline & $6556-01 \mathrm{G}$ & 79 & 0,0438 & 4,6 & 0,0032 & 78,7 & 99,26 & $3,96 \mathrm{E}-14$ & 1122 & 15 \\
\hline & $6556-01 \mathrm{H}$ & 79,9 & 0,0412 & 11,1 & 0,0057 & 79,6 & 98,94 & 2,72E-14 & 1132 & 21 \\
\hline & 6556-01I & 79,8 & 0,0385 & 11,9 & 0,01324 & 77,4 & 96,19 & $6,37 \mathrm{E}-14$ & 1108 & 13 \\
\hline & $6556-01 \mathrm{~J}$ & 107,7 & 0,0543 & 117 & 0,1178 & 88,6 & 75,6 & $2,85 \mathrm{E}-14$ & 1224 & 35 \\
\hline & $6556-02 \mathrm{~A}$ & 115,3 & 0,071 & 65 & 0,227 & 54,9 & 45,5 & $8,21 \mathrm{E}-15$ & 850 & 87 \\
\hline & $6556-02 B$ & 172,5 & 0,082 & 19,5 & 0,3295 & 76,6 & 43,84 & $6,10 \mathrm{E}-14$ & 1100 & 27 \\
\hline & $6556-02 \mathrm{C}$ & 90,6 & 0,0298 & 2,1 & 0,0725 & 69,2 & 76,3 & $5,16 \mathrm{E}-14$ & 1018 & 17 \\
\hline & $6556-02 \mathrm{D}$ & 72,3 & 0,0223 & 5,7 & 0,0184 & 67,5 & 93 & 2,29E-14 & 999 & 25 \\
\hline & $6556-02 \mathrm{E}$ & 70,7 & 0,0141 & -5 & 0,0153 & 65,5 & 93 & $1,19 \mathrm{E}-14$ & 976 & 36 \\
\hline & $6556-02 \mathrm{~F}$ & 67,8 & 0,014 & 0 & 0,0154 & 63,2 & 93,2 & $6,32 \mathrm{E}-15$ & 949 & 59 \\
\hline & $6556-02 \mathrm{G}$ & 82,1 & 0,0254 & 35 & 0,0366 & 75,7 & 90 & $9,54 \mathrm{E}-15$ & 1090 & 55 \\
\hline & $6556-02 \mathrm{H}$ & 84,2 & 0,0302 & 38,4 & 0,0453 & 75,6 & 87,4 & $2,66 \mathrm{E}-14$ & 1089 & 24 \\
\hline & 6556-02I & 111,1 & 0,0418 & 144 & 0,162 & 81,9 & 66,4 & $1,59 \mathrm{E}-14$ & 1155 & 55 \\
\hline & 6556-02J & 140,6 & 0,0603 & 195 & 0,264 & 88,8 & 54,6 & $2,27 \mathrm{E}-14$ & 1225 & 59 \\
\hline
\end{tabular}




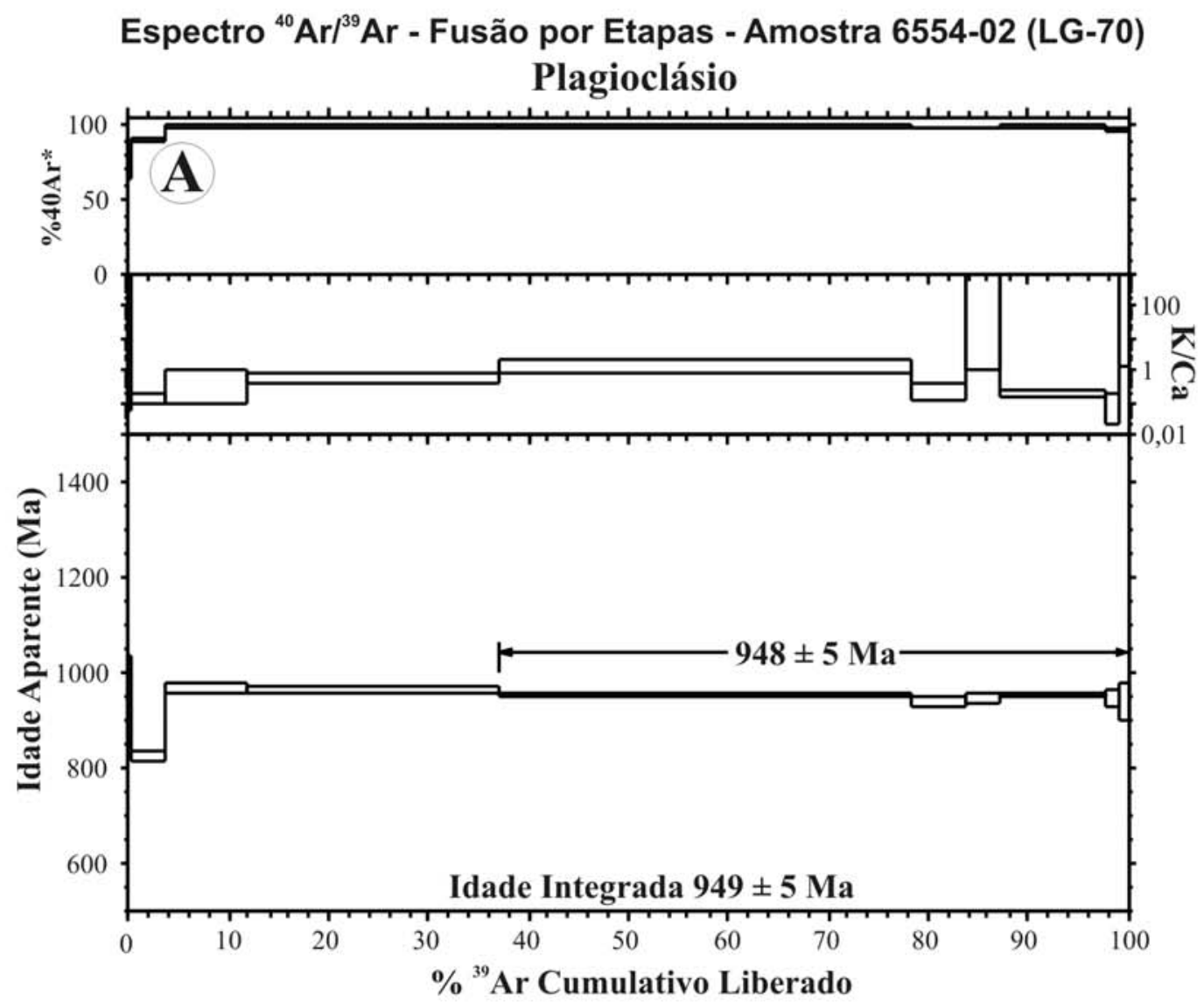

Espectro ${ }^{40} \mathrm{Ar} /{ }^{39} \mathrm{Ar}$ - Fusão por Etapas - Amostra 6556-02 (LG-70)

Anfibólio

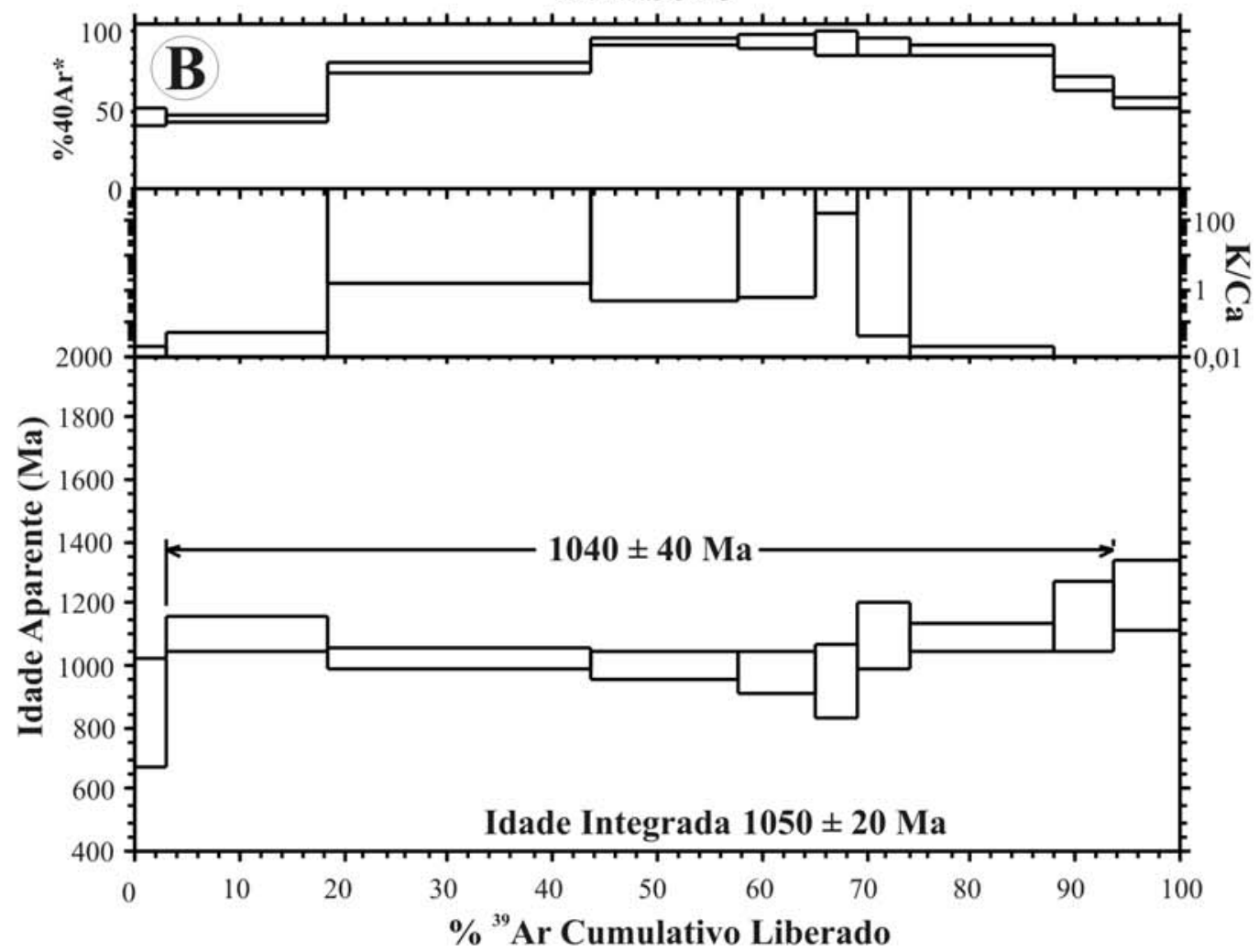

Figura 10 - Diagramas ${ }^{40} \mathrm{Ar}{ }^{\beta 9} \mathrm{Ar}$ (mineral) da amostra LG-70 da Suíte Intrusiva Huanchaca. A) Plagioclásio e B) Anfibólio (hornblenda). 
constante. Por se tratar de rochas indeformadas, a idade do anfibólio $(1040 \pm 40 \mathrm{Ma})$ é a melhor estimativa da idade de injeção/colocação dos sills. A idade do plagioclásio (948 $\pm 5 \mathrm{Ma})$ é, provavelmente, uma idade de resfriamento abaixo da isoterma de $c a .200^{\circ} \mathrm{C}$.

CONCLUSÕES Os sills máficos, objeto deste estudo, ocorrem no Terreno Paraguá, em sua porção não afetada pelo retrabalhamento crustal provocado pela Orogenia Sunsás, e encontram-se alojados segundo a orientação dos estratos da Formação Vale da Promissão, Grupo Aguapeí.

Macroscopicamente, as rochas dos sills são maciças de granulação fina a média variando de melanocráticas a ultramáficas e cor cinza-esverdeado a preta. Apresentam texturas equi a inequigranulares e composição, predominantemente, gabroica. Opticamente, são rochas holocristalinas, de granulação fina a média, textura subofítica a ofítica e, mais raramente, intergranular. São constituídas, essencialmente, por minerais máficos (piroxênios e anfibólios) e plagioclásio, e, em algumas delas, feldspato alcalino e quartzo com intercrescimento gráfico. A olivina é encontrada em poucas amostras que correspondem a cumulatos perfazendo até $40 \%$ de seu volume modal. Como minerais de alteração pós-magmática e acessórios destacam-se: biotita, clorita, talco, titanita, apatita, argilo-minerais, epidoto/clinozoizita, sericita, calcita e serpentina.

Geoquimicamente, as rochas classificam-se como basaltos andesíticos, de natureza subalcalina do tipo toleítica, com destacado enriquecimento em $\mathrm{FeO}_{\mathrm{t}}$ em relação aos álcalis, gerado em ambiente geotectônico correspondente à intraplaca continental. $\mathrm{O}$ índice de diferenciação $\mathrm{mg \#}$ varia entre 0,25 e 0,38 sugerindo magma basáltico evoluído. No diagrama multielementar observam-se anomalias positivas de $\mathrm{Ba}$ e $\mathrm{La}$, e negativas de $\mathrm{K}, \mathrm{Sr}$, Ti e $\mathrm{Nb}$, esta última característica de ambiente continental. Os padrões de distribuição dos elementos terras raras apresentam-se fortemente fracionados e enriquecidos em ETR leves em relação aos ETR pesados e uma discreta anomalia de Eu. As pequenas diferenças das razões $\mathrm{Zr}$ versus elementos incompatíveis observadas sugerem que os sills da Suíte Intrusiva Huanchaca resultam de fonte mantélica homogênea, enriquecida em LILE e empobrecida em $\mathrm{Nb}$ e Ti.

Os dados isotópicos $\mathrm{Ar}-\mathrm{Ar}$ indicaram idades plateaus (platôs) de $1040 \pm 40$ Ma para o anfibólio e $948 \pm 5$ Ma para o plagioclásio, a primeira (anfibólio) é a melhor estimativa da idade de injeção/colocação dos sills. Considerando que os sills máficos estudados apresentam idades de resfriamento dentro do intervalo obtido para os diques das Suítes Intrusivas Rancho de Prata (MT) e Rio Perdido (MS) e Huanchaca (BO) e os sills máficos da Suíte Intrusiva Salto do Céu (MT), sugerimos que o magmatismo investigado constitui parte de uma Large Igneous Province (LIP) toniana evoluída na porção sul-sudoeste do Cráton Amazônico.

Do ponto vista geotectônico, os sills máficos Huanchaca e demais unidades correlatas retratam um evento magmático fissural relacionado aos processos de extensão e ruptura crustal que precederam a dispersão do Supercontinente Rodínia.

Considerando o trabalho de revisão de Li et al. (2008) que afirma que o Supercontinente Rodínia interagiu com plumas mantélicas que resultaram em amplos rifteamentos e rupturas continentais entre 825 e $740 \mathrm{Ma}$, os dados Ar-Ar obtidos para os sills indicam que neste setor do Cráton Amazônico, o processo de extensão e ruptura do Rodínia não foi sincrônico e teve início logo após a sua aglutinação.

Agradecimentos Os autores agradecem à FAPEMAT (Proc. $n^{\circ} 448287 / 2009$ ), CAPES (PROCAD $n^{\circ} 096 / 2007$ ), FAPESP (Proc. $n^{\circ}$ 07/59531-4) e ao GEOCIAM (Instituto Nacional de Ciência e Tecnologia de Geociências da Amazônia) pelo suporte financeiro ao desenvolvimento da pesquisa. A primeira autora agradece a CAPES pela concessão de bolsa de mestrado e ao Programa de Pós-graduação em Geociências/UFMT.

\section{Referências}

Araújo H.J.T., Santos Neto A., Trindade C.A.H., Pinto J.C.A., Montalvão R.M.G., Dourado T.D.C.; Palmeira R.C.B., Tassinari C.C.G. 1982. Projeto RADAMBRASIL - Folha SF. 21 - Campo Grande. Rio de Janeiro, mapa geológico, escala 1:1.000.000.

Araújo L.M.B. 2003. Caracterização petrológica, geoquímica e geocronológica do Maciço Sararé - Nova Lacerda - MT. Dissertação de Mestrado, Instituto de Geociências e Ciências Exatas, Universidade Estadual Paulista de Rio Claro, Rio Claro, 89 p.

Barros A.M., Silva R.H., Cardoso O.R.F.A., Freire F.A.,
Souzajr J.J., Rivetti M., Luz D.S., Palmeira R.C., Tassinari C.C.G. 1982. Projeto RADAMBRASIL - Folha SD.21.- Cuiabá. Rio de Janeiro, mapa geológico, escala 1:1.000.000.

Bettencourt J.S., Leite Jr. W.B., Ruiz A.S., Matos R., Payolla B.L., Tosdal R.M. 2010. The Rondonian-San Ignacio Province in the SW Amazonian Cráton: An Overview. Journal of South American Earth Sciences, 29:28-46.

Boynton W.V. 1984. Cosmochemistry of Rare Earth Elements: Meteorite Studies. In: Henderson P. (ed.) Rare Earth Element Geochemistry. Amsterdan, Elsevier, p. 63-114. 
Boger S.D., Raetz M., Giles D., Etchart E., Fanning C.M. 2005. U-Pb Age data from the Sunsas Region of eastern Bolivia, evidence for the allochthonous origin of the Paragua Block. Precambrian Research, 139:121-146.

Cordani U.G., Tassinari C.C.G., Teixeira W., Basei M.A.S., Kawasita K.1979. Evolução Tectônica da Amazônia com base nos dados geocronológicos. In: Congresso Geológico Chileno, 2, Atas, p. 137-48.

Cordani U.G. \& Brito Neves B.B. 1982.The geologic evolution of South America during the Archean and early Proterozoic. Rev. Bras. Geoc., 12(1-3):78-88.

Corrêa da Costa P.C., Girardi V.A.V., Matos J.B., Ruiz A.S., Correia C.T. 2008. Contribuição ao estudo petrológico e geoquímico das rochas máficas-ultramáficas da região de Vila Bela da Santíssima Trindade-MT, Porção Sudoeste do Cráton Amazônico. Geociências, 27:287-298.

Corrêa da Costa P.C., Girardi V.A.V., Matos J.B., Ruiz A.S. 2009. Geocronologia Rb-Sr e Características Geoquímicas dos Diques Máficos da Região de Nova Lacerda e Conquista D’Oeste (MT), Porção Sudoeste do Cráton Amazônico. Geologia USP. Série Científica, 9:115-132.

D’Agrella Filho M.S., Tohver E., Tamura L.N., Trindade R.I., Ruiz A.S., Silva J.A. 2010. Paleomagnetic and ${ }^{40} \mathrm{Ar} /{ }^{39} \mathrm{Ar}$ geochronological data of Mesoproterozoic mafic dykes from Nova Lacerda, Amazonian Cráton. In: AGU, The Meeting of the Americas, 1, Abstracts, p. 5.

Deino A. \& Potts R. 1990. Single-crystal ${ }^{40} \mathrm{Ar} /{ }^{39} \mathrm{Ar}$ dating of the Olorgesailie Formation, southern Kenya rift: Journal of Geophysical Research, 95:8453-8470.

Elming S.Å., D’Agrella-Filho M.S., Page L.M., Tohver E., Trindade R.I.F., Pacca I.I.G., Geraldes M.C., Teixeira W. 2009. A palaeomagnetic and ${ }^{40} \mathrm{Ar} /{ }^{39} \mathrm{Ar}$ study of Late Precambrian sills in the SW part of the Amazonian Craton: Amazonia in the Rodínia reconstruction. Geophys. J. International, 178:106-122.

Geraldes M.C., Van Schmus W.R., Condie K.C., Bell S., Teixeira W., Babinski M. 2001. Proterozoic geologic evolution of the SW part of the Amazonian Cráton in Mato Grosso state, Brazil. Precambrian Research, 111:91-128.

Irvine I.N. \& Baragar W.R.A. 1971. A Guide To The Chemical Classification Of The Common Volcanics Rocks. Canadian Journal Earth Science, 8:523-548.

Kerr P.F. 1959. Optical Mineralogy. 3.ed., New York, Mcgraw-Hill Book Co., 442 p.

Kuiper K.F., Deino A., Hilgen F.J., Krijgsman W., Renne P.R., Wijbrans J.B. 2008. Synchronizing Rock Clocks of Earth History. Science, 320:500-504.

Le Bas M.J., Le Maitre R.W., Streckeisen A., Zanettin B.A. 1986. Chemical Classification Of Volcanic Rocks Based On Total Alkali-Silica Diagram. Journal of Petrology, 27:745-750.

Li Z.X., Bogdanova S.V., Collins A.S., Davidson A., De WaeleB., Ernst R.E., Fitzsimons I.C.W., Fuck R.A., Gladkochub D.P., Jacobs J., Karlstrom K.E., Lul S., Natapov L.M., Pease V., Pisarevsky S.A., Thrane K., Vernikovsky V. 2008. Assembly, configuration, and break-up history of Rodinia: A synthesis. Precambrian Research, 160:179-210.
Lima G.A. 2008. Geologia da Porção Nordeste da Serra Ricardo Franco (MT) - Região da Fazenda Paredão: ênfase nas Soleiras Máficas-Ultramáficas da Suíte Intrusiva Huanchaca. Trabalho de Conclusão de Curso, Instituto de Ciências Exatas e da Terra, Universidade Federal de Mato Grosso, Cuiabá, 64 p.

Litherland M., Annells R.N., Appleton J.D., Berrangé J.P., Bloomfield K., Burton C.C.J., Darbyshire D.P.F., Fletcher C.J.N., Hawkins M.P., Klinck B.A., Llanos A., Mithcell W.I., O’Connor E.A., Pitfield P.E.J., Power G.E, Webb B.C. (eds.) 1986. The Geology and Mineral Resources of the Bolivian Precambrian Shield. London, Her Majesty's Stationery Office, $140 \mathrm{p}$.

MacKenzie W.S., Donaldson C., Guilford C. (eds.) 1982. Atlas of Igneous Rocks and their Textures. New York, John Wiley and Sons, 148 p.

Matos J.B., Schorscher J.H.D., Geraldes M.C., Sousa M.Z.A., Ruiz A.S. 2004. Petrografia, geoquímica e geocronologia das rochas do Orógeno Rio Alegre, Mato Grosso: um registro de crosta oceânica Mesoproterozóica no SW do Cráton Amazônico. Geologia USP. Série Científica, 4:75-90.

McDonough W.F. \& Sun S.S. 1995. The composition of the earth. Chemical Geology, 120:223-253.

Monteiro H., Macedo P.M., Silva M.D., Moraes A.A., Marchetto C.M.L. 1986. O 'Greenstone Belt' do Alto Jauru. In: SBG, Congr. Bras. Geol., 34, Anais, p. 630-647.

Pearce J.A. \& Norry M. J. 1979. Petrogenetic implications of Ti, $\mathrm{Zr}$, Y and $\mathrm{Nb}$ variationsi Volcanic Rocks. Contrib. Mineral. Petrol, 69:33-47.

Richard L.R. 1995. Minpet For Windows - Version 2.0: Reference Manual Minpet Geological Software. Quebec, 1995.

Ruiz A.S. 2005. Evolução Geológica do Sudoeste do Cráton Amazônico Região Limítrofe Brasil-Bolívia - Mato Grosso. Tese de Doutorado, Instituto de Geociências e Ciências Exatas, Universidade Estadual Paulista, Rio Claro, $250 \mathrm{p}$.

Ruiz A.S. 2009. Compartimentação Tectônica (Pré-Sunsás) do SW do Cráton Amazônico: ênfase em Mato Grosso - Brasil. In: Congreso Geológico Boliviano, 18, Actas, p. 159-163.

Ruiz A.S., Simões L.S.A., Corrêa da Costa P.C., Matos J.B., Araújo L.M.B., Godoy A.M., Sousa M.Z.A. 2005. Enxames de diques máficos (Suíte Intrusiva Rancho de Prata) no SW do Cráton Amazônico: indícios de colapso extensional no Orógeno Sunsás? In: SBG, Simp. de Vulcanismo e Ambientes Associados, 3, Atas, p. 297-302.

Ruiz A.S., Sousa M.Z.A., Lima G.A., Batata M.E.F. 2009. Soleiras e diques máficos tonianos do SW do Cráton Amazônico: Provável Registro da Ruptura do Supercontinente Rodínia. In: SBG, Simp. Geol. Centro Oeste, 11, Atas, p. 58.

Ruiz A.S., D’Agrella Filho M.S., Sousa M.Z.A., Lima G.A. 2010a. Tonian sills and mafic dike swarms of S-SW Amazonian Cráton: records of Rodinia Supercontinent break-up? In: The Meeting of the Americas, 1, Abstracts, p. 3.

Ruiz A.S., Matos J.B., Sousa M.Z.A., Lima G.A., Batata M.E.F. 2010b. Mapeamento Geológico e Levantamento 
de Recursos Minerais da Folha Santa Bárbara (SD.21$Y-C-V)$. Cuiabá, CPRM/UFMT, Relatório Etapa de Mobilização, 35 p.

Saes G.S. 1999. Evolução Tectônica e Paleogeográfica do Aulacógeno Aguapeí (1.2 - 1.0 Ga) e dos Terrenos do seu embasamento na porção sul do Cráton Amazônico. Tese de Doutorado, Instituto de Geociências, Universidade de São Paulo, São Paulo, 135 p.

Saes G.S. \& Fragoso César A.R.S. 1996. Acresção de terrenos mesoproteróicos no SW da Amazônia. In: SBG, Cong. Bras. de Geologia, 39, Resumos Expandidos, p. 348.

Santos R.O.B., Pitthan J.H.L., Barbosa E.S., Fernandes C.A.C., Tassinari C.C.G., Campos D.A. 1979. Projeto RADAMBRASIL - Folha SD.20 - Guaporé. Rio de Janeiro, mapa geológico, escala 1:1.000.000.

Santos J.O.S., Hartmann L.A., Gaudette H.E., Groves D.I., Mcnaughton N.J., Fletcher I.R. 2000. A new understanding of the Amazon Cráton Provinces based on integration of field mapping and $\mathrm{U}-\mathrm{Pb}$ and $\mathrm{Sm}-\mathrm{Nd}$ Geochronology, Gondwana Research, 3:453-488.

Santos J.O.S., Rizzotto G.J., Potter P.E., Mcnaughton N.J., Matos R.S., Hartmann L.A., Chemale Jr F., Quadros M.E.S. 2008. Age and Autochthonous Evolution of The Sunsás Orogen in the West Amazon Cráton based on mapping and U-Pb Greochronology. Precambrian Research, 165:120-152.

Sécolo D.B., Ruiz A.S., Sousa M.Z.A., Lima G.A., Batata M.E.F. 2008. Caracterização Geológica e Petrográfica do Enxame de Diques Máficos (Suíte Intrusiva Huanchaca) no Domínio Tectônico Paraguá - SW do Cráton Amazônico - MT. In: SBG, Cong. Bras. Geologia, 44, Anais, p. 545.

Tassinari C.C.G. 1981. Evolução Tectônica da Província Rio Negro-Juruena na Região Amazônica. Dissertação de Mestrado, Instituto de Geociências, Universidade de São Paulo, São Paulo, 99 p.
Tassinari C.C.G. 1996. O Mapa Geocronológico do Cráton Amazônico no Brasil: revisão dos dados isotópicos. Tese de Livre-Docência, Instituto de Geociências, Universidade de São Paulo, São Paulo, 139 p.

Tassinari C.C.G. \& Macambira M.J.B. 1999. Geochronological Provinces Of The Amazonian Cráton. Episodes, 38:174-182.

Tassinari C.C.G., Bettencourt J.S., Geraldes M.C., Macambira M.J.B., Lafon J.M. 2000. The Amazonian Cráton. In: Cordani U.G., Milani E.J., Thomaz-Filho A., Campos D.A. (eds.) Tectonic Evolution of South America - 31 ${ }^{\text {st }}$ IGC. Rio de Janeiro, CPRM, p. 41-95.

Tassinari C.G.C., Macambira M.J.B. 2004. A Evolução Tectônica do Cráton Amazônico. In: Neto-Mantesso V., Bartorelli A, Carneiro C.D.R., Brito-Neves B.B. (eds) Geologia do Continente Sul-Americano: Evolução da Obra de Fernando Flávio Marques de Almeida. São Paulo, Editora Beca, p. 471-486.

Teixeira W., Tassinari C.C.G., Cordani U.G., Kawashita K. 1989. A review of the Geochronoloy of the Amazonian Cráton: Tectonic Implications. Precambrian Research, 42:213-227.

Teixeira W., Geraldes M.C., Matos R., Ruiz A.S., Saes G., Vargas-Mattos G. 2010. A Review of the tectonic evolution of the Sunsás Belt, SW Amazonian Cráton. Journal of South American Earth Sciences, 29:47-60.

Vasconcelos P.M., Onoe A.T., Kawashita K., Soares A.J., Teixeira W. 2002. ${ }^{40} \mathrm{Ar} /{ }^{39} \mathrm{Ar}$ geochronology at the Instituto de Geociências, USP: instrumentation, analytical procedures, and calibration: Anais da Academia Brasileira de Ciências, 74:297-342.

Manuscrito ID 20779

Submetido em 15 de fevereiro de 2011 Aceito em 07 de fevereiro de 2012 